\title{
Review of Curie point depth determination through different spectral methods applied to magnetic data
}

\author{
Núñez Demarco, P. ${ }^{1,2, *}$, Prezzi, C. ${ }^{2}$, Sanchez Bettucci, L. ${ }^{1,3}$
}

${ }^{1}$ Instituto de Ciencias Geológicas, Facultad de Ciencias - Universidad de la República, Montevideo, Uruguay

${ }^{2}$ IGeBA, CONICET - Universidad de Buenos Aires. Dpto. de Cs. Geológicas, Facultad de Ciencias Exactas y Naturales - Universidad de Buenos Aires, Buenos Aires, Argentina

${ }^{3}$ Dirección Nacional de Minería y Geología, Montevideo, Uruguay

*corresponding author: Pablo Núñez Demarco, pnunez@fcien.edu.uy abbreviated title: Review of Curie depth spectral methods

\section{Abstract}

Spectral methods have been applied for more than 40 years to calculate the depth to magnetic sources and the Curie point depth or Moho depth. Unfortunately, conceptual, theoretical and methodological errors, as well as, subjective approaches and lack of rigor in the application of the method are common. This has affected reproducibility, credibility and confidence in this method.

We carried out a detailed mathematical and methodological revision of the spectral methods (centroid, spectral peak, forward and fractal methods) applied to magnetic data for the determination of the depth to magnetic sources. Moreover, a systematic analysis of more than 110 articles was done in order to compile and compare the different approaches and values of key parameters used by different authors in their calculations. We discuss difficulties, conditions and methodological procedures, as well as several misapplications and misinterpretation of the different methods.

Keywords: Magnetic anomalies: modelling and interpretation, Fourier analysis, Fractals and multifractals. 


\section{Introduction}

Currently, several methods are applied to calculate the depth to magnetic sources from magnetic anomaly maps. Since Spector \& Grant (1970) proposed a general procedure to determine the depth to magnetic sources through the power spectrum of magnetic profiles or maps, the spectral analysis has gained popularity, thanks to advances in modern computing; making it one of the simplest and fastest methods to obtain a depth estimate of the magnetic sources.

From the analysis of the crustal magnetic field, it is possible to estimate the depth below which no magnetization could exist. Under the proper conditions, $Z_{b}$ (Deep Base/Bottom of Magnetic Sources, DBMS also referred to as Depth to Bottom, DTB) can be related to the depth at which rocks lose their magnetic properties due to the interior Earth temperature, that is, when rock minerals reach its Curie temperature or Néel temperature (Langel \& Hinze, 1998). As a result, $\mathrm{Z}_{\mathrm{b}}$ is often considered synonymous with the Curie isotherm depth-also known as Curie Point Depth- although this might not always be the case.

Rocks magnetization depends on composition (amount of magnetic minerals) and temperature. In fact, thickness estimates of the magnetized earth's crust suggest that there can be two limits corresponding to vertical changes in composition and/or temperatures at which rocks lose their ferromagnetic properties. In this regard, $Z_{b}$ (Fig. 1) can sometimes represent a petrological limit (Rajaram et al, 2009; Langel \& Hinze, 1998; Blakely, 1988). At depth, the composition of the crust can change, so that rocks become poor in magnetic minerals. In regions of very low thermal flux (e.g. shield areas) the Curie isotherm can be found below the Moho, but as the mantle rocks are often believed to be non-magnetic (according to studies of xenolith samples) $\widehat{Z}_{\mathrm{b}}$ depth in those regions may correspond to the Moho instead of to the Curie isotherm (Wasilewski et al., 1979; Wasilewski and Mayhew, 1992). Some cases in Brazil (Gasparini et al., 1979), Siberia (Bulina, 1961), and Canada (Hall, 1968) show this peculiarity. However, some studies have concluded that the upper mantle can also contribute to the geomagnetic field in some tectonic environments (e.g. Saad, 1969; Chiozzi et al., 2005; Ferré et al., 2013, 2014; 
Friedman et al., 2014). For example, in regions with low thermal flux (Eppelbaum and Pilchin, 2006) or alternatively in regions with thin crust as in oceanic regions (Harrison \& Carle, 1981; Arkani-Hamed \& Strangway 1986; Counil et al., 1989; Langel \& Hinze, 1998) Curie isotherm depth is most likely reached in the upper mantle rather than in the crust.

When $Z_{b}$ correlates with a velocity or density limit, it most likely reflects a compositional change. However, when it does not coincide with such kind of limits, it more likely reflects the depth to Curie isotherm (Beardsmore and Cull, 2001). In the latter case, $Z_{b}$ value allows us to estimate the depth at which Curie temperature is reached and, therefore, the geothermal gradient in the studied zone. For this reason, it is important to consider the magnetic mineralogical composition of the crust. Since most of the minerals are paramagnetic or diamagnetic with extremely low magnetic susceptibilities, the magnetic properties of rocks are mainly controlled by ferromagnetic minerals. The main carrier of magnetization is given by the Titanomagnetite solid solution series. Other minerals such as hematite, pyrrhotite and iron and nickel alloys are only considered important in certain spatially restricted geological situations; however, it is still a topic under discussion (e.g. Kletetschka et al., 2002; McEnroe et al., 2004). Therefore, it is considered that the main magnetic minerals in the lower crust are magnetite or titanomagnetites (Frost and Shive, 1986; Hunt et al., 1995). The titanomagnetite series consists of the variable solid solution of its two extreme minerals: magnetite and ulvospinel. Its physical properties vary with the ratio of titanium to iron; a higher concentration of titanium results in a lower Curie temperature, as wefl as a lower magnetic susceptibility. Generally, for the deepest sources, magnetite is considered as the main magnetic mineral. Therefore, it is assumed that the Curie temperature of magnetite determines the temperature of the Curie isotherm (Telford et al., 1990). However, the Curie temperature of magnetite is $580{ }^{\circ} \mathrm{C}$ when it is pure, but it can drop down to $300{ }^{\circ} \mathrm{C}$ for titanium magnetite or rise up to 620 or $1100{ }^{\circ} \mathrm{C}$ for $\mathrm{Fe}-\mathrm{Co}-\mathrm{Ni}$ alloys (Haggerty, 1978; Blakely, 1998). The generalization of $580{ }^{\circ} \mathrm{C}$ as the temperature of Curie isotherm is a reasonable approximation for the continental crust (Ross et al., 2006), but it should be considered with appropriate caution. 
Additionally, the Hopkinson effect in the mid to lower crust must be taken into account (Hopkinson, 1889). This is a second order magnetic phase transition, between ferro/ferrimagnetic and paramagnetic states, that at the Curie temperature can induce a very sharp (theoretically infinite) increase of the magnetic susceptibility. This can produce zones few hundred of meters thick, with extremely high susceptibility, just at the Curie depth. If this effect is not taken into account, the magnetic anomalies caused by such bodies could be interpreted to be caused by very large size bodies with normal susceptibilities (Kiss et al., 2005; Dunlop et al., 2010; Dunlop, 2014). This may be particularly important for magnetic multilayer models of the crust.

The usual methodology to calculate the depth to magnetic sources from magnetic anomaly maps involves calculating the power spectrum of the magnetic data of a defined area, then calculating the radial average of the power spectrum, and finally fitting the experimental curve with some theoretical curve, which depends directly on the depth to the magnetic source (Fig 1). This method can be applied to the entire data set to obtain a single regional average depth, or the studied area can be divided into smaller zones (windows). In this last case, local depth values are obtained, and a map of the depth to the magnetic sources can be generated for the whole studied area. The principal complications of this methodology are given by the dimensions of the studied area, the resolution or detail with which it is intended to map the depth to the magnetic sources, and the theoretical model used.

Despite its apparent simplicity, methodological flaws, inaccuracies and/or errors in the application of the different methods - even for the simplest model- are frequently found in the literature. Moreover, some authors barely indicate which model or conditions were applied (e.g. Azab, 2014; Elitok \& Dolmaz, 2008; Ikumbur et al., 2013; Xiong et al., 2016; Li et al., 2017; Mono et al., 2018, Astort et al., 2019, Usman et al., 2019). In many cases, curve fitting is made by hand (completely or partially) which does not represent a problem, except because, in the pursuit of a geologically coherent result, several validity conditions are usually neglected. This handicraft component, allied to insufficient knowledge of the theoretical and practical limitations of each method, and to an unrigorous treatment of a large number of secondary 
parameters (that are not always clearly stated) contributes to making this method somehow dubious and obscure.

In this paper, we review different published methods (centroid, forward modeling, spectral peak and fractal methods) emphasizing their limitations, validity conditions, problems and sensitive points. This paper is organized as follows: Section 2 summarizes the theoretical basis of the Curie depth spectral methods, subsection 2.1 offers guidelines on different practical aspects, compiling common pitfalls and errors, clarifying conditions and results interpretations that should be considered in the application of the method. Section 3 presents the theoretical foundation and conditions for the application of forward modeling and spectral peak methods. Meanwhile, Section 4 condenses the theoretical foundation and conditions of the fractal model, and Section 5 continues with a simplified version of the fractal method. Subsequently, we summarize some practical aspects that should be considered previous to the application of all the methods in Section 6. We address the issues of the data windows: geometry, sizes and overlapping and we analyze windowing, filtering and reduction to the pole aspects in Section 7. Section 8 discusses the different ways to calculate the geothermal gradient from the Curie depth estimates. Finally, in Section 9 we present the conclusions and guidelines for the method application. As supplementary material, we share the MATLAB ${ }^{\circledR}$ scripts to reproduce all the figures and results presented in this paper.

\section{Basic Spectral Model}

Spector \& Grant (1970) introduced a procedure by which the depth to the top of the magnetic source can be determined, using the radial mean of the energy spectrum. The procedure was later improved by other authors (Treitel et al., 1971; Bhattacharyya \& Leu, 1975a,b, 1977; Okubo 1985; Tanaka et al., 1999) allowing to calculate not only the depth to the top of the magnetic sources but also the depth of its centroid and its bottom, using the radial mean of the 
Assuming that $(i)$ the magnetic source is a layer that extends infinitely in all horizontal directions, that (ii) the thickness of the layer is small compared to the horizontal scale, and that (iii) the magnetization $M(x, y)$ is a random function of $x$ and $y$, and does not depend on depth; Blakely (1996) showed, theoretically, that the power spectral density (or simply power spectrum) of the total anomalous magnetic field observed is given by:

$$
\mathrm{P}\left(n_{x}, n_{y}\right)=\Phi_{M}\left(n_{x}, n_{y}\right) \times G\left(n_{x}, n_{y}\right)
$$

where $n_{x}, n_{y}$ are the wavenumbers in the $x$ and $y$ directions, so that $n_{i}=2 \pi / \lambda_{i}$, where $\lambda_{i}$ is the wavelength in the $x$ or $y$ directions (in real discrete conditions $\lambda_{i}=k . d_{i}$, with $\mathrm{k}$ being an integer and $d_{i}$ the discrete element separation or wavelength resolution), $\Phi_{M}$ is the magnetization power spectrum and $G$ is the Fourier transform of the anomalous total field, given by:

$$
G\left(n_{x}, n_{y}\right)=4 \pi^{2} C_{M}^{2}\left|\theta_{M}\right|^{2}\left|\theta_{C G}\right|^{2} e^{-2|n| Z_{t}}\left(1-e^{-|n|\left(Z_{b}-Z_{t}\right)}\right)^{2}
$$

where $C_{\mathrm{M}}$ is a constant, $\theta_{M}$ and $\theta_{C G}$ are factors for the direction of magnetization and the direction of the geomagnetic field respectively, $Z_{t}$ is the depth to the top of the magnetic layer, $Z_{b}$ is the depth to the bottom of the magnetic layer, and $|n|$ is the module of $\left(n_{x}, n_{y}\right)$. Also, the expression $\Phi_{M}\left(n_{x}, n_{y}\right)$ is a constant, if the magnetization $M(x, y)$ is a completely random and uncorrelated function of $x$ and $y$.

Eq. (2) can be simplified since all its terms are radially symmetric; with the exception of $\theta_{M}$ and $\theta_{C G}$ that are not radially symmetric, but their radial mean is a constant. Therefore the radial average of the power spectrum can be simplified as:

(3) $\quad P(|n|)=A e^{-2|n| Z_{t}}\left(1-e^{-|n|\left(Z_{b}-Z_{t}\right)}\right)^{2}$ 
where $A$ is a constant. Applying logarithm to both sides of the equation yields:

$$
\ln [P(|n|)]=\ln [A]-2 Z_{t}|n|+2 \ln \left[1-e^{-|n|\left(Z_{b}-Z_{t}\right)}\right]
$$

For medium to high values of $n$, the exponential term goes to zero, and the logarithm also approaches zero. Hence, eq. (4) corresponds to a line with slope equal to $2 Z_{t}$ :

$$
\ln [P(|n|)]=\ln [A]-2 Z_{t}|n|
$$

Dividing (5) by 2 gives:

$$
\ln \left[[P(n)]^{1 / 2}\right]=B-Z_{t}|n|
$$

where $n$ is the wave number, $P(n)$ the power spectrum, $Z_{t}$ is the depth to the top of our magnetic layer and $B$ is a constant.

Therefore, we can calculate the power spectrum of our magnetic anomaly data, then the radial average of the power spectrum and finally determine the slope for long wavelengths and thus obtain the depth to the top of the magnetic layer, using eq. (6).

On the other hand, rearranging terms and multiplying by $e^{|n|\left(Z_{o}-Z_{o}\right)}$, eq. (3) can be rewritten as:

$$
[P(|n|)]^{1 / 2}=A e^{-|n| Z_{o}}\left(e^{-|n|\left(Z_{t}-Z_{o}\right)}-e^{-|n|\left(Z_{b}-Z_{o}\right)}\right)
$$

where $Z_{o}=\left(Z_{b}-Z_{t}\right) / 2$ is the distance from the surface to the layer centroid.

Substituting the last exponential terms of eq. (7) by the first terms of their Taylor series 


$$
[P(|n|)]^{1 / 2} \sim A e^{-|n| Z_{o}}|n|\left(Z_{b}-Z_{t}\right)
$$

being $\left(Z_{b}-Z_{t}\right)$ the thickness of the magnetic layer. Hence, applying logarithm to eq. (8) and rearranging terms leads to:

(9) $\quad \ln \left[\frac{[P(n)]^{1 / 2}}{|n|}\right]=\ln [D]-Z_{o}|n|$

where $n$ is the wave number, $P(n)$ the power spectrum, $Z_{o}$ the depth to the centroid of the magnetic layer and $D$ a constant that depends on the thickness of the magnetic layer. Consequently, from the radial average of the power spectrum scaled by the spatial frequency of our data, we can calculate the slope for the first values of $n$ and obtain the centroid depth of the magnetic layer.

Additionaly, the depth to the bottom of the magnetic layer follows the relationship (Okubo et al.. 1985; Tanaka et al.. 1999):

$$
Z_{b}=2 Z_{o}-Z_{t}
$$

where $Z_{b}$ is the depth to the base of the layer, $Z_{o}$ the depth to the centroid and $Z_{t}$ the depth to the top of the layer.

The application of eqs (6), (9) and (10) for the characterization of magnetic bodies in depth is known as the centroid method.

\subsection{Considerations about the centroid method}

Despite the simplicity of this method, there are many errors, omissions or misinterpretations of

it. The depths $Z_{t}$ and $Z_{o}$ not only should be calculated in completely different ranges of $n$, but also must be calculated using different equations (eqs 6 and 9). This is not a minor problem 
since, there are several publications that calculate $Z_{t}$ and $Z_{o}$ in the same wavenumbers ranges (e.g. Ates et al., 2005; Bansal et al., 2011; Zaher et al., 2018; Guimaraes et al., 2014; Elbarbary et al., 2018; Quintero et al., 2019) or in different ranges but using the same curve (e.g. Bello et al. 2017, Idarraga-García \& Vargaz, 2018; Aliyu et al., 2018). Moreover, some publications use the wrong equations or units (Usman et al., 2018). Errors like these automatically invalidate the results obtained, since they lack physical and geological meaning. This emphasizes the importance of theoretical and methodological rigor in scientific publications. Consequently, below, we discuss some fundamental aspects for the correct application of the method:

\subsubsection{Unit systems}

Wavenumber units are another source of confusion, as was noticed by Ravat et al. (2007). Wavenumbers can be expressed in radians $/ \mathrm{km}$ (also noted as $2 \pi / \mathrm{km}$ ) or cycles $/ \mathrm{km}$ (also $1 / \mathrm{km})$. Even, sometimes wavenumbers can be substituted by the spatial frequency also expressed in $1 / \mathrm{km}$ units (this is a well known problem with dimensionless units, see Mohr \& Phillips, 2014). In addition, ground units can be in meters or kilometers. This aspect, added to the fact that wavenumbers and equations are usually used without specifying the units, has led to several confusions (Ravat et al., 2007). Here, we use wavenumbers expressed in $\mathrm{rad} / \mathrm{km}$. However, if the wavenumber is expressed in cycles $/ \mathrm{km}$, or if frequencies expressed in $1 / \mathrm{km}$ are used, eqs (6) and (9) should be corrected by a $2 \pi$ factor, so that $Z=$ slope $/ 2 \pi$ (see Okubo et al., 1985; Ravat et al., 2007). Additionally, it is important to emphasize that spectral method equations can be expressed using either the power spectral density $\mathrm{P}(n)$ or the amplitude spectral density $[\mathrm{P}(n)]^{1 / 2}$ involving different factors (corrections) in the slope - for example, notice that eqs (5) and (6) differ by a factor of 2 in the slope -. The same occurs with the frequency scaled power spectral density $\mathrm{P}(n) /|n|$, and the frequency scaled amplitude spectral density $[\mathrm{P}(n)]^{1 / 2} /|n|$. This means that if the power spectrum is used (as in eq. 5), the depth should be corrected by a factor of $2(Z=$ slope/2), but if the amplitude spectrum is used (as in eq. 6) no correction is needed when wavenumbers are in $\mathrm{rad} / \mathrm{km}$. However, if wavenumbers are in cycle/km then the combined correction factors should be $4 \pi$ and $2 \pi$, respectively. Therefore, a confusion with the 
unit system can imply a huge error or difference in results. For example, if any author obtained results between 1 and $40 \mathrm{~km}$ using incorrect units, then such results could have errors ranging between 12 and $500 \mathrm{~km}$ if the correction factor of $4 \pi$ was not applied. . Despite the warnings of several authors (e.g. Ravat et al., 2007, Bonde et al., 2014), this is still a point of confusion: some publications seem to have wrong corrections because their equations and wavenumber units are not consistent between them (e.g. Dolmaz et al., 2005a; Qingqing et al., 2008; Bilim et al., 2011; Hisarli et al., 2011, Githiri et al., 2012; Saleh et al., 2012; Hsieh et al., 2014; Afshar et al., 2016; Mousa et al., 2017; Aydemir et al., 2018; Quintero et al., 2019), some others use a wrong unit system (e.g. Azab, 2014; Usman et al., 2018).

\subsubsection{Wavenumber ranges}

Other of the complexities of the method lies in defining the wayenumber ranges in which $Z_{t}$ and $Z_{o}$ should be calculated. Most of the authors (see table 1) do not specify these wavenumber ranges, and usually, select them by hand according to the pattern observed in each spectrum. The range used by different authors to calculate $Z_{0}$ oscillates substantially (see table

1). In some cases, $Z_{o}$ is calculated in narrow ranges $(0$ to $0.05 \mathrm{rad} / \mathrm{km})$, while in others it is calculated in extremely wide ranges ( 0 to $0.4 \mathrm{rad} / \mathrm{km})$. Meanwhile, $Z_{t .}$ is calculated in ranges as diverse as $0-0.04$ and $0-31 \mathrm{rad} / \mathrm{km}$. Table 1 summarizes the different wavenumber ranges used in 72 previously published papers. Among the 72 surveyed articles (Table 1) only 8 (11\%) explicitly explained in which wavenumber interval $Z_{t}$ was calculated, and only five used fixed intervals. In 43 articles, the used intervals can be deduced to some extent from their sample figures, although as they are representative of some particular cases, the ranges used in each study could be even larger than indicated in Table 1 . Notice also that, as the majority of the authors do not use fixed intervals, we indicated the maximum ranges in which $Z_{t}$ and $Z_{o}$ were calculated along with each analyzed publications. Concurrently, in $14(19 \%)$ articles no information at all is provided about the wavenumber ranges used. An outstanding exception is the paper of Bansal et al. (2011) that shows all the wavenumber ranges selected for each one of their 31 analyzed windows. 
However, the validity of the approximation between eqs (4) and (5) establishes the mathematical conditions in which $Z_{t}$ can be calculated. In the same way, the relationship between eqs (7) and (8) determines the conditions in which the linear approximation to calculate $Z_{o}$ is valid. The wavenumber values in which the linear approximation is valid (or accurate) can be calculated through the mathematical difference in slope between the linear approximation and the theoretical curve, given by:

$$
\text { slope difference }=\left|\frac{f\left(n_{i+1}\right)-f\left(n_{i}\right)}{n_{i+1}-n_{i}}-\frac{g\left(n_{i+1}\right)-g\left(n_{i}\right)}{n_{i+1}-n_{i}}\right| .
$$

Where $f(n)$ is the theoretical curve, $g(n)$ is the linear approximation, and $n$ the wavenumber. Fig. 2 shows the percentage difference in slope and curves between eqs (4) and (5) and Fig. 3 the percentage difference in slope and curves between eqs (7) and (8), for different values of $Z_{t}$, $Z_{o}$ and $n$. Logarithm was applied to eqs (7) and (8), that also were divided by the $\ln (n)$ previous slope difference calculation, so the slopes represents depths as in eq. (9). In this context the slope difference is directly the difference in depth between the linear approximation and the theoretical curve. In the regions in which the linear adjustment to $Z_{t}$ and $Z_{o}$ are valid, the slope difference should tend toward zero. Figs 2 and 3 show that these validity regions depend on $n$ and $\Delta Z=\left(Z_{b}-Z_{t}\right)=2 .\left(Z_{o}-Z_{t}\right)$ and that variation in $Z_{t}$ does not modify substantially the results.

It can be observed that $Z_{t}$ ean be calculated confidently in almost all ranges of $n>0.05$ $\mathrm{rad} / \mathrm{km}$, where eqs (4) and (5) show a good fit, with a difference of less than $5 \%$ between them (Fig. 2a-h). In general, the confidence region to calculate $Z_{t}$ is larger. $Z_{t}$ can be confidently calculated at $n>0.1$ or $0.3 \mathrm{rad} / \mathrm{km}$. Moreover, the error can be extremely large close to zero $(\mathrm{n}<$ $0.05 \mathrm{rad} / \mathrm{km}$ ), reaching values 100 times larger than the real $Z_{t}$ (Notice that in Fig. 2 the color bar is saturated at $100 \%$ slope difference). However, very precise values (less than $5 \%$ error) can be obtained in the proper $n$ region. The precise measurement region depends on the thickness of the magnetic layer $(\Delta \mathrm{Z})$ and on $Z_{t}$ (Fig. 2a-d). In this regard, despite eqs (4) and (5) show an apparent good fit at $\mathrm{n}=0.05$ or $0.1 \mathrm{rad} / \mathrm{km}$ (Figs $2 \mathrm{e}, \mathrm{f}, \mathrm{g}, \mathrm{h}$ ) the results in that regions 
can differ between $0 \%$ to $100 \%$ depending on $\Delta \mathrm{Z}$ and $Z_{t}$ values (compare Figs. 2a and d). For example, an error of $1 \mathrm{~km}$ in deep interfaces may be negligible but it becomes unacceptable if it involves locating shallow sources. For deep sources, with $Z_{t}$ larger than $5 \mathrm{~km}$ (see Fig $2 \mathrm{c}, \mathrm{d}$ ), $Z_{t}$ should be calculated at $n>0.05 \mathrm{rad} / \mathrm{km}$. Meanwhile, for sources less than $40 \mathrm{~km}$ thick, $Z_{t}$ should be calculated at $n>0.1$ or $0.2 \mathrm{rad} / \mathrm{km}$. For shallow sources, with $Z_{\mathrm{t}}$ less than $5 \mathrm{~km}, Z_{t}$ can be calculated confidently at $n>0.2 \mathrm{rad} / \mathrm{km}$ if the source is more than $40 \mathrm{~km}$ thick; and, at $n>0.3$ $\mathrm{rad} / \mathrm{km}$ if the source thickness is between 20 and $40 \mathrm{~km}$. However, for shallow sources less than $20 \mathrm{~km}$ thick, $Z_{t}$ needs larger and larger wavenumbers to be calculated. Moreover, for laminar sources, less than $2 \mathrm{~km}$ thick (regardless of $Z_{t}$ value), the method to calculate $Z_{t}$ seems to be impractical, as the error becomes larger than the results.

On the other hand, the linear approximation to calculate $Z_{o}$ shows an inverse behavior (Fig. 3). The range of wavenumbers in which the linear approximation is valid increases as $\Delta Z$ approaches to zero. For magnetic layers more than $50 \mathrm{~km}$ thick, the linear approximation is only valid (with a difference less than $20 \%$ ) between 0 and $0.02 \mathrm{rad} / \mathrm{km}$ or less. For magnetic layers with thicknesses between $50 \mathrm{~km}$ and $25 \mathrm{~km}$, the linear approximation is valid for wavenumbers from 0 to $0.05 \mathrm{rad} / \mathrm{km}$. For magnetic layers with thicknesses between $25 \mathrm{~km}$ and $10 \mathrm{~km}$, the linear approximation is valid for wavenumbers from 0 to $0.1 \mathrm{rad} / \mathrm{km}$. If the magnetic layer is less than $10 \mathrm{~km}$ thick, the valid range can be extended to larger and larger wave numbers. For practical purposes, the range of wavenumbers between 0 and $0.05 \mathrm{rad} / \mathrm{km}$ appears to be the most confident region to calculate $Z_{0}$, especially when $Z_{t}$ and $\Delta Z$ are unknown. Moreover, $Z_{o}$ confidence region is less sensitive to $Z_{t}$ variations.

From Table 1 it can be observed that 30 out of $68(44 \%)$ articles calculate $Z_{t}$ in the appropriate wavenumber ranges $(n>0.05)$ and 21 out of $68(30 \%)$ calculate $Z_{t}$ in regions that include invalid regions $(n<0.05)$ or are too narrow and close to sensitive regions $(0.05<n<$ $0.2)$. Meanwhile, only 3 out of $63(4 \%)$ calculate $Z_{o}$ in the pertinent wavenumber region $(n<$ $0.05)$, and $5(8 \%)$ in wavenumbers less than $0.1 \mathrm{rad} / \mathrm{km}$. This fact is outstanding, as some of the calculations carried out in the wrong wavenumber region can lead to more than $40 \mathrm{~km}$ of error, totally invalidating their results. Curiously, the wavenumber region, in which it is 
methodologically valid to calculate $Z_{o}$, is usually avoided or filtered, since it is considered that results obtained from such range are overestimated or affected by long-wavelength noise caused by surface anomalies, topographic features or regional fields (Tanaka et al., 1999; Okubo et al., 1985; Blakely, 1988; Ravat et al., 2007; Trifonova et al., 2009; Bansal et al., 2013).

\subsubsection{Model interpretation}

Other problems arise from the application and interpretation of the described method. In the basic method proposed by Blakely (1996), the magnetic source is a single layer with random magnetization. However, if the magnetic body is composed of multiple magnetic layers (strata, lava flows, sills, flood basalts), $Z_{t}$ and $Z_{o}$ calculations will correspond to the average values of these layers, leading to an incorrect estimate and interpretation of $Z_{b}$ (Spector \& Grant, 1970; Hildenbrand et al., 1993; Okubo \& Matsunaga, 1994; Chiozzi et al. 2005; Ravat et al. 2007). In their model, Spector \& Grant (1970) assumed that the studied magnetic anomaly is produced by a large number of randomly arranged blocks at different depths, but, they showed (following the postulates of statistical mechanics) that the general power spectrum follows the average of the power spectra of all magnetic sources (like in Blakely (1996) model). Moreover, $Z_{t}$ and $Z_{o}$ could reflect signals from different layers; $Z_{t}$ could indicate the top of the most superficial layer, but it may not be the same layer in which the centroid $Z_{o}$ is determined, and consequently, $Z_{b}$ will yield a meaningless result (Spector \& Grant, 1970; Okubo \& Matsunaga, 1994; Ravat et al., 2007). Additionally, Spector \& Grant (1970) indicate that in the special case of two magnetic sources, and when the bottom of the deeper source cannot be detected, the spectrum can be spread in two parts, reflecting the two magnetic sources. Despite this, some authors interpret their results assuming a multilayer model. They calculate several $\mathrm{Z}_{\mathrm{t}}$ and $Z_{o}$ in different ranges of $n$, arguing that the different slopes observed in the spectrum reflect the distinct layers involved (e.g. Connard et al., 1983; Hildenbrand et al., 1993; Nwobgo, 1998; Ebbing et al., 2009; Abbass \& Mallam, 2013; Guimaraes, 2014; Azab, 2014; Saibi et al., 2015; Gomes et al., 2015; Harrouchi et al., 2016; Abderbi et al., 2017; Mousa et al., 2017). However, the theoretical background for such interpretations is not clear, as it contradicts the 
mathematical conditions of the applied model. Moreover, García-Abdeslem \& Ness (1994) proved through modeling that spectrum slope changes, "which quite often are interpreted as intermediate magnetic horizons", arises as the result of the horizontal dimensions of the source, and not because of the presence of a second or third source (see also Spector \& Grant, 1970; Okubo et al., 2003).

We tested the multilayer scenario, constructing four synthetic models composed of three layers each one (Fig. 4). Figs 4 (a) through (d) show the models, the spectrum produced by each layer and the spectrum resulting from adding the individual spectra (continuous black line). Layers' spectra were calculated using eq. (3), which only depends on $Z_{t}, Z_{b}$ and the constant $A$ in which the magnetic properties of the body are condensed. The first model (Fig. 4a) is a trivial reference model, composed by three layers with the same constant $A$ value. The second model (Fig. 4b) uses the same configuration as the first one, but giving different values to the constant $A$ for each layer. The third model (Fig. 4c) simulates a superficial layer with strong magnetization, which could represent a magnetized basin or flood basalts. Conversely, the fourth model (Fig. 4d) simulates a deep layer with very strong magnetization, which can be considered a first approximation to the Hopkinson effect. In all the models $Z_{t}$, and $Z_{b}$ were calculated using eq. (6), (9) and (10) in all the discrete segments of the curves corresponding to each layer and in the sum of spectra (Figs $4 \mathrm{e}-1$ ) (note that the sum of spectra and the average of the spectra have the same slope when the logarithm is applied). In all models $Z_{t}$ plots (Fig 4e-h) show that for the individual spectrum $Z_{t}$ value converges to the real depth to the top of each layer, while in the case of the sum of the spectra $Z_{\mathrm{t}}$ converges to the value corresponding to the uppermost layer (the area in which $Z_{\mathrm{t}}$ should not be calculated is shown in gray; see Fig. 2). However, in the second model, if the values are estimated in low wavenumbers, $Z_{\mathrm{t}}$ can reflect intermediate values between the ones of the two most superficial layers (Fig. 4f). $Z_{b}$ plots (Fig 4i-1) show that $Z_{\mathrm{b}}$ roughly converges to the real depth to the bottom of each layer near zero; a circle in the plots indicates when calculated values match real $Z_{\mathrm{b}}$. The sum spectra of the layers converge, in all cases, to the depth to the bottom of the deepest layer. However, in the first, second and fourth model $Z_{b}$ measured under the valid region exceeds the actual value. The effect 
is particularly noticeable in the fourth model where the curve reaches the validity region outside the scale. These results show how sensitive $Z_{b}$ can be to the configuration of the sources.

Besides, it can be seen that for wavenumbers $>0.2 \mathrm{rad} / \mathrm{km}$ values calculated from the average spectrum converge to values close to the $Z_{\mathrm{b}}$ of the most superficial layer (Figs $4 \mathrm{i}-\mathrm{k}$ ). However, the results are variable depending on the configuration; in the second model $Z_{b}$ values between 0.2 and $0.5 \mathrm{rad} / \mathrm{km}$ are deeper than the $Z_{\mathrm{b}}$ of the most superficial layer; meanwhile in the fourth model values between 0.2 and $0.5 \mathrm{rad} / \mathrm{km}$ are shallower than the $Z_{\mathrm{b}}$ of the most superficial layer. Moreover, these examples show that intermediate layer values cannot be calculated safely since any intermediate $Z_{b}$ can be obtained.

It should be noted that in these synthetic models we are looking at theoretical/spectra; real spectra would also contain noise. Moreover, if the layer is very deep, the signal will be quickly overprinted by noise, hindering the calculation of the slope and adding new error sources. Furthermore, in a real scenario, slopes are measured at specific intervals of the spectrum, which results in an average slope of that interval. This "averaging" helps to overcome noise problems and to reduce deviation of overestimations and underestimations.

Furthermore, the method also requires sources with random magnetization. However, this assumption involves gross geological oversimplifications that must be carefully analyzed (Blakely, 1988). Several geological settings do not fulfill this requirement. Oceanic crust, for example, is well known by its linear alternating magnetic pattern, and has been avoided in most studies (although there are some exceptions, e.g. Harrison \& Carle, 1981; Li, 2011; Li et al., 2013, 2017; Gailler et al., 2016; Tanaka, 2017). However, Wang \& Liu (2018) modeled oceanic crust and its effects on the power spectra. These authors concluded that source depths in the oceanic crust can still be estimated using the power spectra. Although, the best results are obtained when using the power spectra perpendicular to oceanic anomalies. Nevertheless, they also show that the radial averaged power spectra yields a good estimate of the real depth. 


\section{Forward modeling and spectral peak methods}

The set of eqs (6), (9) and (10) constitutes the simplest and most widely used methods to determine the depth to the top and bottom of a magnetic layer. A somewhat more elaborated solution involves adjusting the theoretical curve corresponding to eq. (3) to the magnetic data power spectrum. Rewriting of eq. (3) yields a more elegant and practical equation for this adjustment:

$$
P(n)=A\left[e^{-Z_{t}|n|}-\mathrm{e}^{-Z_{b}|n|}\right]^{2}
$$

where $\mathrm{A}$ is a constant that does not depend on the depths $Z_{t}$ and $Z_{b}$. This is a two variables equation that should be iteratively adjusted until finding the minimum misfit between the observed power spectrum and this theoretical curve (see Blakely, 1996; Ravat, 2007). The application of this equation is known as the forward modeling method. Examples of theoretical curves are shown in Fig. 5.

Other proposed method involves the determination of the maximum peak in the power spectrum $P\left(n_{\max }\right)$ in order to calculate $Z_{t}$ and $Z_{b}$ through their relation to the corresponding wavenumber $n_{\max }$ (Connard et al., 1983; Blakely, 1996). The corresponding theoretical equation can be obtained by finding the zeros of the first derivative of Eq. (12). The solution is given by:

$$
n_{\text {max }}=\frac{\operatorname{Ln}\left(Z_{t}\right)-\ln \left(Z_{b}\right)}{Z_{t^{-}} Z_{b}}
$$

This equation also requires an iterative solution, by trial and error, in which the values of $Z_{t}$ and $\mathrm{Z}_{\mathrm{b}}$ are estimated a priori.

Figs 5a-i highlights the spectral peak in each curve, while the constant A must be positive, and its value simply scales the theoretical curve up or down (Figs 5a, b, c). $Z_{t}$ and $Z_{b}$ 
values affect the position of the spectral peak and also scale the curve up and down (Figs $5 f$, i). $Z_{t}$ controls the shape of the curve, especially for large wavenumbers. Moreover, the spectral peak becomes narrower as $Z_{t}$ increases (Figs $\left.5 \mathrm{a}, \mathrm{b}, \mathrm{c}, \mathrm{g}, \mathrm{h}, \mathrm{i}\right)$. For shallow bodies $\left(Z_{\mathrm{t}}<10\right.$ or $Z_{\mathrm{b}}<10 \mathrm{~km}$ ) variations in $Z_{\mathrm{t}}$ and $Z_{b}$ produce huge changes in the position of the spectral peak (see Figs $5 \mathrm{~d}, \mathrm{~g}$ ). As $Z_{\mathrm{b}}$ becomes larger, variations in spectral peak position due to changes in $Z_{\mathrm{t}}$ become smaller (Figs 5d, e, f). As $Z_{t}$ gets larger, and bodies get deeper, differences in peak position become smaller (see Figs $5 \mathrm{~g}, \mathrm{~h}, \mathrm{i}$ ). In consequence, for deeper bodies, with large $\mathrm{Z}_{\mathrm{t}}$ and $Z_{\mathrm{b}}$, differences in spectral peak positions become minimal (see Figs 5e, f, h, i). Additionally, amplitude becomes larger as the difference between $Z_{\mathrm{t}}$ and $Z_{\mathrm{b}}$ becomes larger (see Figs $5 \mathrm{~d}$, e, f). Fig. 5(k) shows the wavenumber solutions of eq. (13), this means the spectral peak positions, for different configurations of $Z_{\mathrm{t}}$ and $Z_{\mathrm{b}}$. Notice that spectral peak position varies slightly between 0 and $0.1 \mathrm{rad} / \mathrm{km}$ when $Z_{\mathrm{t}}$ and $Z_{\mathrm{b}}$ are both larger than $\sim 10 \mathrm{~km}$.

The limitations of the spectral peak method lie in the identification of the peak, sometimes nonexistent, and also in the non-uniqueness of solutions. Blakely (1996) warns that this determination depends on the smallest wavenumbers parts of the spectrum and that this region is susceptible to noise from various sources, Ravat et al. (2007) carried out a careful analysis, concluding that this method offers better results if large windows are used, since, according to these authors, the spectral peaks are present if windows are large enough as to capture good signals at low wavenumbers (Rajaram et al., 2009; Ravat et al., 2007). However, according to their study, spectral peaks in the radial power spectrum are observed only when the source is randomly magnetized (as prescribed by Spector \& Grant, 1970). When the source is a layer composed of an ensemble of uniformly magnetized prisms, the spectrum follows a power law and no spectral peak is observed (Ravat et al., 2007). If the magnetic source follows a fractal distribution - with a fractal coefficient larger than or equal to three - there will not be a spectral peak (fractal models are discussed in section 4, see also Todoeschuck et al., 1992; Maus et al., 1997; Bouligand et al., 2009; Bansal et al., 2011; Chopping \& Kennett, 2013; among others). Moreover, the possibility of finding the spectral peak also depends on the resolution of the power spectrum. Due to the discrete nature of the power spectrum, the 
maximum point in the spectrum usually is close to but does not exactly correspond to the spectral peak, resulting in inaccurate determinations of the real position of the peak. This issue can be very problematic, particularly in the case of deep bodies where subtle differences in $n_{\max }$ result in large depth differences (see Fig. 5k).

Spectral peak and forward modeling methods are inter-related. This means that if the spectral peak cannot be calculated, the forward model cannot be applied, because eq. (12) is not valid when the spectral peak does not exist.

\section{Fractal model}

The previous methods are based on the assumption that the magnetic sources are distributed in layers or prisms (Bhattacharyya, 1964; Spector \& Grant, 1970; Blakely, 1996). However, these geometries do not always reflect the natural variations of the parameters in the Earth.

It was Mandelbrot (1983) who introduced the concept of fractal distributions (scaling noises), providing a realistic model for the spectral power density of various parameters in nature. A source with fractal distribution has a power spectrum proportional to $n^{-\beta}$, where $n$ is the wavenumber and $\beta$ is the respective fractal exponent. This exponent determines the proportions between the variations of the high and low frequencies of the signal. The greater the value of the exponent, the greater the ratio of the long to the short wavelengths in the signal. A distribution of scaling noises with a Gaussian probability density is completely characterized by its mean, variance and scalar exponent. Despite it is unlikely that the geophysical variables present such simple variations, the scalar noise model is a good first approximation of the real behavior in geology. Nowadays many geophysical processes are described according to fractal terms. Hosken (1980) determined that acoustic reflections in well studies follow a fractal distribution. Hewett (1986) found that so does porosity (neutron density). Todoeschuck et al. (1992) determined that density, resistivity and $\gamma$ profiles follow the same law, and that rock properties would seem fundamentally fractal. Brown \& Scholz (1985), Scholz \& Aviles (1986) 
and Hirata et al. (1987) demonstrated that fractures, faults and faulting also follow fractal distributions.

Gregotski et al (1991) and Todoeschuck et al. (1992) observed that magnetic field anomalies appear to exhibit the power law characteristic behavior and suggested that this behavior could reflect a fractal distribution of the magnetization in the crust. According to several authors, this model introduces significant improvements in the calculation of the depth to the magnetic source (Maus \& Dimri, 1995). The fractal model (Todoeschuck et al., 1992; Maus \& Dimri, 1995; Maus et al., 1997; Bansal \& Dimri, 2005; Bouligand et al., 2009; Bansal \& Dimri, 2013; Chopping \& Kennett, 2013) assumes that the radial average of the logarithm of the power spectrum follows the following general equation (Maus et al., 1997):

(14)

$$
\begin{aligned}
\ln [P(|n|)]= & \frac{1}{2 \pi} \int_{0}^{2 \pi} \ln (P(n, \varphi)) d \varphi \\
= & \underbrace{\frac{1}{2 \pi} \int_{0}^{2 \pi} \ln \left[c_{s} \frac{\mu_{o}^{2}}{N^{2}}\left(V^{2}+H^{2} \cos ^{2}(\varphi)\right)^{2}\right] d \varphi-2|n| Z_{t}-|n| \Delta Z-\beta \ln (n) \ldots}_{C} \\
& +\ln \left[\int_{0}^{\infty}[\cosh (\Delta Z|n|)-\cos (\Delta Z V)]\left(1+\frac{V^{2}}{|n|^{2}}\right)^{-1-\frac{\beta}{2}} d V\right]
\end{aligned}
$$

Where $Z_{t}$ is the height above the layer of magnetic sources of thickness $\Delta Z=\left(Z_{b}-Z_{t}\right), \mu_{o}$ is the permeability of free space, $\boldsymbol{N}$ is the geomagnetic field vector (to which the remanent magnetization is paralle1), $H$ and $V$ are the horizontal and vertical component of the geomagnetic field respectively, $n=\left(n_{x}, n_{y}, n_{z}\right)$ is the wavevector and $|n|$ the norm of the horizontal wavenumbers $|n|=\sqrt{\left(n_{x}^{2}+n_{y}^{2}\right)}$. Cs and $\beta$ are constants; where $\beta$ is the 3D scalar exponent of the susceptibility distribution, also called the fractal exponent.

This equation can be solved analytically, arriving at the following expression (Bouligand et al., 2009): 
(15)

$$
\begin{gathered}
\ln [P(|n|)]= \\
C-2|n| Z_{t}-(\beta-1) \ln (|n|)+\left[-|n| \Delta Z+\ln \left(\frac { \sqrt { \pi } } { \Gamma ( 1 + \frac { \beta } { 2 } ) } \left(\frac{\cosh (|n| \Delta Z)}{2} \Gamma\left(\frac{1+\beta}{2}\right)-\right.\right.\right. \\
\left.\left.\left.\mathrm{K}_{\frac{1+\beta}{2}}(|n| \Delta Z)\left(\frac{|n| \Delta Z}{2}\right)^{\frac{1+\beta}{2}}\right)\right)\right]
\end{gathered}
$$

Where $C$ is a constant, $\Gamma$ is the gamma function and $\mathrm{K}$ is the modified Bessel function of the second type. This solution has four unknown variables, $C, \mathrm{Z}_{\mathrm{t}}, \Delta \mathrm{Z}$ and $\beta$, which must be set iteratively until finding the best fit with the power spectrum measured. Fig. 6 shows how the variation of parameters $\beta, Z_{\mathrm{t}}, Z_{\mathrm{b}}$ and $\Delta \mathrm{Z}$ affect the theoretical curve (eq. 15), considering a shallow source (Fig. 6a, b, c, d), a deep source (Fig. 6e, f, g, h), and the difference between a thin and a thick source (Fig. 6i, j, 1, m). In addition, Bouligand et al, (2009) show the influence of each one of these parameters and the problems in the calculations. A model with these characteristics has several possible solutions and requires a large amount of computing time and evaluation of the results. To simplify the processing, these parameters must be previously estimated, establishing the range of variation expected for them, so that the model does not give with geologically inconsistent solutions (Bouligand et al., 2009; Chopping \& Kennett, 2013). Also, due to the practical difficulties in the application of this method only a few articles used it (e.g. Maus et al., 1997; Bouligand et al., 2009; Chopping \& Kennett, 2013; Salem et al., 2014; Mather \& Fullea, 2019).

Divergences arise regarding the order in which certain operations must be applied in the method. In the centroid methods of Spector \& Grant (1970) and Blakely (1996) the radial mean is calculated first and subsequently, the logarithm is applied in order to solve the equations. This is the order followed by successive researchers. However, in the fractal method, Maus \& Dimri $(1995,1996)$ and Maus et al. (1997) propose a modification in the order in which the operations are applied; instead of calculating the logarithm of the radial average of the power spectrum, 
they propose to calculate the radial average of the logarithm of the power spectrum. That is, apply the logarithm before obtaining the radial average. Maus \& Dimri (1995) point out that the estimates of the exponent and the depth to the source can differ by more than $20 \%$ when applying these operations in a different order. Besides, these authors indicate that the distribution of both curves is different and that the (linear) mean only has mathematical meaning if it is applied on the averaged logarithmic spectrum and not on the logarithmic averaged spectrum. Maus \& Dimri (1995) postulated that this makes the power spectrum independent of the direction of the magnetic field and, therefore, reduction to the pole is not necessary when applying this method.

\section{Simplified fractal method}

Eq. (15) can be simplified, considering that the final term of the equation - in square brackets - tends to zero when $n$ or $\Delta Z$ become larger (Figs 6i-1 and 7). In fact, for $\Delta Z$ larger than $10 \mathrm{~km}$, and $n$ greater than $0.1 \mathrm{rad} / \mathrm{km}$ eq. (15) is independent of the value of $Z_{\mathrm{b}}$ (see Figs $6 \mathrm{i}-1$ ). In consequence eq. (15) can be simplified to:

$$
\begin{aligned}
\ln [P(|n|)] & =C-2|n| Z_{t}-(\beta-1) \ln (|n|) \\
& =C-2|n| Z_{t}-\ln \left(|n|^{\alpha}\right)
\end{aligned}
$$

with $\alpha=\beta-1$. (At this point readers should be cautious, as exponent notations are slightly different in different publications). Fig. 7 shows a comparison between results obtained from eqs (15) and (16) under different conditions. This approach implies that the power spectrum follows the general equation (Pilkington \& Todoeschuck, 1993; Pilkington et al., 1994; Maus \& Dimri, 1995, 1996; Li \& Eaton, 2004; Bansal et al., 2011; Bansal \& Dimri, 2013):

$$
\text { (17) } \quad P(n)=C^{\prime} e^{-2 Z_{t}|n|}|n|^{-\alpha}
$$


with $C=\ln \left(C^{\prime}\right)$. Also, according to Pilkington \& Todoeschuck (1993) and Li \& Eaton (2004), $C=8 \alpha ! ! / \pi(\alpha+1) ! !$ where the notation $k ! !$ is the double factorial or semifactorial of a number $k$. Eq. (16) or (17) can also be rewritten as a linear equation of the form:

$$
\ln \left[P(n) \cdot|n|^{\alpha}\right]=C-2 Z_{t}|n|
$$

This set of equations (analogous to eq. 6) is only valid for $n$ larger than 0.1 or $0.2 \mathrm{rad} / \mathrm{km}$ (Fig. 7) and allow the estimation of $Z_{t}$.

On other hand, Bansal et al. (2011, 2013) and Bansal \& Dimri, (2013) suggested a simplified fractal equation for the calculation of $Z_{0}$ :

$$
\ln \left\lceil\frac{P(n)}{|n|^{2}} \cdot|n|^{\alpha}\right\rceil=D-2 Z_{o}|n|
$$

However, this equation was proposed without a clear mathematical foundation nor explanation of its validity conditions; although it is purportedly valid for long wavelengths (in the same way as eq. 9) (see Bansal et al., 2011). In fact, this equation implies that:

$$
\begin{aligned}
\ln [P(n)] & =D-2 Z_{o}|n|-(\alpha-2) \ln [n] \\
& =D-2 Z_{o}|n|-(\beta-3) \ln [n\rceil
\end{aligned}
$$

which is similar to eq, (16) but changing $Z_{t}$ by $Z_{o}$ and reducing the fractal constant. As can be seen in Fig. 7 that shows the comparison between eqs (20), (15) and (16) in different conditions - eq (20) approaches to the behavior of eq. (15) for low wavenumbers (long wavelenghts). Meanwhile, eq. (16) approaches to eq. (15) for all except long wavelengths (Fig. $7)$.

Fig. 8 shows the percentage difference in the slope of the curves corresponding to eq. (16) and eq. (15), (following eq. 11), for varying values of $Z_{t}$ and $Z_{b}$ fixed at $100 \mathrm{~km}$. Variations 
in the constant $C$ or $\beta$ produce the same results. Eq. (16) has a good fit along almost all the spectra for wavenumbers larger than $0.05 \mathrm{rad} / \mathrm{km}$. The pattern slightly changes when $\mathrm{Z}_{\mathrm{t}}$ approximates to $\mathrm{Z}_{\mathrm{b}}$. For practical purposes, $\mathrm{Z}_{\mathrm{t}}$ can be calculated for wavenumbers larger than $0.1 \mathrm{rad} / \mathrm{km}$.

Fig. 9 presents the percentage difference in the slope of the curves corresponding to eqs (20) and (15), following the eq. (11), for varying values of $Z_{b}$ and $\beta$, and $Z_{t}$ fixed at $1 \mathrm{~km}$. Variations in the constant $D$ and $Z_{t}$ values produce the same results.. When the difference between $Z_{b}$ and $Z_{t}$ is greater than $40 \mathrm{~km}$, the approximation between eqs (20) and (15) has less than $10 \%$ of error only in a narrow interval approximately between 0.01 to $0.02 \mathrm{rad} / \mathrm{km}$, for $\beta=1$ and 2 and between 0 to $0.02 \mathrm{rad} / \mathrm{km}$, for $\beta=3$ and 4 . Strikingly, when $Z_{\mathrm{b}}$ approaches to $\mathrm{Z}_{\mathrm{t}}$, and particularly when $\Delta Z$ is less than $10 \mathrm{~km}$, eq. (20) can be adjusted confidently along with larger wavenumbers (Fig. 9). When the difference between $Z_{b}$ and $Z_{t}$ is less than $40 \mathrm{~km}$ and larger than $10 \mathrm{~km}$, the confidence interval position varies notoriously with depth, in a narrow band of $0.02 \mathrm{rad} / \mathrm{km}$, between 0.01 and $0.10 \mathrm{rad} / \mathrm{km}$. This behavior can be particularly useful to establish measuring intervals when real values of $Z_{t}$ and $Z_{b}$ are previously known or constrained, but it can be very problematic (and impractical) if these values are totally unknown, since it would be necessary to test all the different conditions.

\section{Windows: geometry, sizes and overlapping}

Although the geometry of the windows does not affect the calculation of its Fourier transform, for symmetry reasons, in order to capture the same wavelengths in all directions, it is convenient to use square windows.

On the other hand, the window size is a critical parameter in spectral methods, since it constrains, the maximum wavelength that will be captured and, consequently, it determines the maximum depth that will be reached. It is a consensus that source/layer thickness needs to be small in comparison to the window size. However, there is no clear consensus among 
researchers about the dimensions of the windows that should be used. Table 1 summarizes window sizes and overlapping utilized by different authors.

Several authors applied different windows sizes, comparing the corresponding results (e.g. Okubo et al., 2003; Bouligand et al., 2009; Rajaram et al., 2009; Ravat et al., 2007; Quintero et al., 2019). Hussein et al. (2012) argue that windows should have, in general, a size of at least 3 or 4 times the depth of the studied magnetic layer. Manea \& Manea (2011), following Campos-Enriquez et al. (1990), indicate that window dimensions must be $2 \pi$ times the depth to be reached. Yet, Chiozzi et al. (2005) and Ravat et al. (2007) warn that the size of the windows should be 5 to 10 times the depth to the base of the magnetic layer, or even greater. However, Maus et al. (1997) argue that $100 \times 100 \mathrm{~km}$ areas are not large enough to cover all crustal effects, and they state that to obtain reliable results, areas bigger than $1000 \mathrm{~km} \times 1000$ $\mathrm{km}$ should be analyzed. In contrast, Ravat et al. (2007) focusing on the speetral peak method and comparing it with other methods - found that the best results are obtained using windows between 300 and $500 \mathrm{~km}$ wide. These authors admit that windows can be reduced under certain conditions to improve the spatial resolution of the method "if the nature of the spectrum allows it". They recommend starting the analysis with the largest possible window size, in order to ensure that the response of the deepest layers is being captured, and to reduce the size of the windows to gain resolution, keeping the results with large windows as a reference.

Moreover, the usual procedure implies to divide the studied area into numerous windows that overlap between them (e.g.: Okubo et al., 1985; Blakely, 1988; Lesane et al., 2015; Bouligand et al., 2009; Idarraga-García \& Vargaz, 2018; Audet \& Gosselin, 2019). This overlapping allows to increase the data coverage (resolution) and to avoid data loss (of anomalies or frequencies contained in image borders). Additionally, this methodology allows the investigation of lateral variations of basal depth through the studied area, although it can smooth discontinuities and regional changes. Unfortunately, not all the publications inform if the windows overlap or how much they overlap, moreover, the amount of overlapping, between adjacent windows, is arbitrary varying between $0 \%$ and $98 \%$ overlap (see Table 1 ). 


\section{Windowing, Filters and Reduction to the Pole}

Most magnetic anomaly data correspond to grids. A grid is simply an $n \times m$ matrix, with $n$ columns and $m$ rows, which can be presented as a map or image. The Fourier's transform assumes that the signal is periodic in all directions, in other words, it assumes that the signal is infinitely repeated, or that the image can be infinitely tiled in all directions. Consequently, the transitions between the repeated images (i. e. the edges of the tiles) also become part of the analyzed signal. If there is a large difference between the opposite edges of an image, it will generate an abrupt discontinuity in the signal. These discontinuities are of large bandwidth and can mask other relevant components in the spectrum (Brigham, 1988; Moisan, 2011; Mahmood et al., 2015; Burger \& Burge, 2016; Audet \& Gosselin, 2019).

There are several possible solutions to this problem. One solution consists in multiplying the image by a frame (taper) function in order to smooth the image along its edges, assigning them an average value, in this way the transitions between tiles are almost eliminated (Ravat et al., 2007; Espinosa \& Campos, 2008; Manea \& Manea, 2011). This method is called tapering or windowing. However, according to the convolution theorem when functions are multiplied a new pattern is generated by the frame function in the Fourier spectrum, distorting the results. Additionally, this method can obliterate some low frequencies in window borders. Several windowing functions have been proposed, the most common ones are: Blackman, Hamming and Hann (e.g.. Espinosa \& Campos, 2008; Bansal \& Dimri, 2013). Another common solution is to extend the image. This process assigns new edges with the same average value and fills the space between the image and the new edges with interpolated values through gridding processes. This process does not modify the information in the original signal, but it can also add new signals to the spectrum. Additionally, it is used to complete irregular images and fill holes in them. This method is mentioned in some publications (e.g. Tselentis, 1991; Elitok \& Dolmaz, 2008; Quintero et al., 2019) and used in software like Oasis Montaj. Other solution is by mirroring the image, form $n \times m$ to $2 n \times 2 m$, and making it symmetrical. However, 
this increases by $4 \mathrm{x}$ the size of the image that increase computational requirements, and generates inaccuracies in the phase of the signal. Many other alternative procedures have been proposed (Moisan, 2011; Mahmood et al., 2015) although it is not clear if they are used in spectral methods. Unfortunately, this treatment is considered a minor procedure and only few articles indicate the method used, if any was applied. However, Ravat et al.(2007) warn that low wavenumbers portions of the spectrum can produce false peaks or incorrect spectral estimates due to inappropriate data processing.

Other related issue is the application of filters to the data. Filters are functions that are multiplied with the spectrum of the signal, in order to eliminate some frequencies from it. It is common, in this kind of analysis, to apply filters to eliminate the regional or global field from the magnetic data or to emphasize long wavelengths (e.g. Okubo et al., 1985; Tselentis, 1991; Tsokas et al., 1998; Stampolidis \& Tsokas, 2002; Dolmaz et al., 2005a, b; Elitok \& Dolmaz, 2008; Manea \& Manea, 2011; Selim \& Aboud, 2014; among others). For example, Okubo et al. (1985) and Tselentis (1991) recommended the application of high-pass filters; Dolmaz et al. (2005a, b) used a band pass filter, Selim \& Aboud (2014) applied low-pass filters; meanwhile others eliminated the first component of the field through polynomial approximation, upward continuations or other methods (Li et al 1996; Qingqing et al., 2008; Rajaram et al., 2009; Harrouchi et al., 2016; Abdel Zaher et al. 2018; Aliyu et al., 2018; among others). However, authors like Bansal et al. (2013) and Ravat et al. (2007) challenged this long-held view, warning that the data should not be filtered to eliminate regional fields, because such filtering leads to the elimination of significant information from the spectrum, precisely the information related to the deeper layers, which are of interest in this kind of studies. Moreover, as we show in previous sections, the low wave number zone is crucial for the calculation of $Z_{b}$; filtering this region may involve significant loss of information.

Other authors proposed the application of different filters in order to separate the contributions of the different layers involved (Ridsdill-Smith, 1998; Phillips, 2001; Guimaraes et al., 2014). Although the idea seems logical, this is based on the previously mentioned and wrong assumption, that different segments of the spectra contain exclusively information 
corresponding to different depths. This is like assuming that a multimodal distribution can be separated into its various components simply by taking different segments of the histogram. Moreover, shallow and low-magnetized layers can generate low-frequency signals, while deep, highly-magnetized and restricted sources can generate high frequency responses. As we previously mentioned, the general power spectrum follows the average of the power spectra of all magnetic sources, and as in multimodal distributions, the contributions of different sources cannot be easily separated, unless in very specific cases (Spector \& Grant, 1970; Hildenbrand et al., 1993; Okubo \& Matsunaga, 1994; García-Abdeslem \& Ness, 1994; Ridsdill-Smith, 1998; Okubo et al., 2003; Ravat et al., 2007).

The use of reduced to the pole data, in the different proposed models, is a matter that requires care and further studies. Reduction to the pole is applied to the data to transform the asymmetric shape of dipolar anomalies to symmetric ones, theoretically allowing to more precisely locate anomalies above their source bodies (Baranov, 1957; Baranov and Naudy, 1964; Silva, 1986; Blakely, 1996; Hinze et al., 2012; De Ritis et al., 2013, Dentith and Mudge, 2014). However, reduction to the pole is generally based on the assumption that the magnetization of the sources is parallel to the direction of the ambient field. When bodies present dominant remanent magnetization, with ${ }^{\lambda}$ Koenisberger Ratio (Q) larger than 1, reduction to the pole yields anomalous and non-symmetrical patterns (e.g. Roest and Pilkington, 1993; Ansari \& Alamdar, 2009; Hinze et al., 2012; Dentith and Mudge, 2014). For particular cases and bodies the remanent magnetization can be known and can be used to correct the reduction to the pole of that particular source. However, considering the dimensions of the areas studied with spectral analysis and the geological variability in them, it is expected that some magnetic sources present dominant remanent magnetization while others do not (Okubo et al., 1985; Blakely, 1996; Bektaş et al., 2007). Additionally, reduction to the pole can be complicated either in extensive areas (due to changes in magnetic latitude and longitude) or in low latitude areas (Spector \& Grant, 1970; Maus et al., 1997; Hsieh et al., 2014; Xiong et al., 2016). Moreover, reduction to the pole changes the phases, rather than the frequencies of magnetic anomalies, and therefore, theoretically, it has no effect on the power spectrum 
(Blakely, 1996). However, some reduction to the pole methods had been reported to produce unexpected modifications in low wavenumbers of the spectra (Zhang et al., 2018; Blakely, 1996). Okubo et al. (1985) and Zhou \& Thybo (1998) presented numerical experiments with both model and real data, showing negligible differences between results obtained with and without applying reduction to the pole. However, they decided not to apply it. On other hand, Maus \& Dimri $(1995,1996)$ and Maus et al. (1997) explained that, for the fractal model, if the average is calculated before the logarithm, the spectrum must be reduced to the pole to remove the directional terms. Nevertheless, these authors conclude that, if the average of the logarithm of the power spectrum is calculated, no differences are observed between the curves corresponding to the power spectrum of the data reduced to the pole versus the non-reduced.

\section{Guidelines}

Despite their popularity, spectral methods are not as simple as they seem to be. These methods are full of complications, involving multiple variables and minor methodological procedures that must be carefully selected and reported. The findings after our review have surprised us. As was discussed in these pages, conceptual, theoretical and methodological errors and lack of rigor in the application of the different methodologies are common. Several authors applied the method either using the wrong equations, the wrong conditions, or without reporting any of the methodological conditions and applied procedures. This makes the results in most cases irreproducible. Many variables can affect the results. The use of inappropriate wavenumber intervals, the selected window size, windowing, window extensions or filters, or the fractal constant evaluated, can alter the results. Particularly, depth to bottom (or centroid) of the magnetic sources $\left(\mathrm{Z}_{\mathrm{b}}\right)$ is the most sensitive variable, easily modifiable by the abovementioned factors. This highlights the care that must be taken when applying this method.

\section{Guideline 1: Reproducibility.}

Reproducibility is commonly accepted as a necessary condition for good scientific practice. It does not ensure that the results are correct, but rather it ensures transparency and 
confidence in the results, allowing to understand exactly what was done. In order to avoid manipulation and to allow the reproducibility of the results, the different steps, variables and procedures used must be carefully reported. Authors must assist future researchers by providing enough information about their experiments. Even, reviewers should question if other researchers can replicate the experiments and validate the results from the information provided (see Barr et al. 1995; Fehr et al., 2016; Crick et al., 2017; NASEM, 2019).

\section{Guideline 2: Steps to apply the method.}

All the Curie depth spectral methods have steps in common that involve assumptions, parameters and procedures that should be reported, tested and or discussed.

The selected magnetic anomaly data can be analyzed as a whole or divided in windows (or lines). The authors should define and report windows size and windows overlapping. Window size is related to the depth to be reached. As there is no complete consensus among authors, it is advisable to indicate why that size was chosen. Then, each data window can be filtered or reduced to the pole. Although, we recommend not to filter the data or alter it, otherwise it is advisable to compare results obtained from filtered and unfiltered data. The next step is to prepare each window for the application of the Fourier Transform either applying a taper function, a window extension or mirroring the signal. The selected method must be reported. Then, the Fourier Transform is applied and the power spectrum and its radially average are calculated. These steps are very common procedures, however, minimal variations may occur due to the subtle variations in the equations of the different software (eg: normalization parameters, averaging equations), so we recommend reporting with which software these operations were performed. Some authors apply filters or operations after or between the previous steps. The operations and the order in which they were applied should be reported, and if possible, it should be evaluated how they affect the results.

Next, authors should select the method or several methods to be applied. Each method implies assumptions about the nature of the magnetic sources that should be discussed considering the geological setting studied. Beyond that, some methods are computationally more complex than others. Fitting methods must be applied in theoretically valid regions, and 
the methods used should be reported (even trivial ones). Also, authors should verify that equations and results have consistent units (as we show in this paper, this kind of pitfall is not obvious). Finally, the obtained results should be thoroughly discussed.

\section{Geothermal gradient}

The thermal structure of the lithosphere controls several aspects of geotectonic and geodynamic evolution. Usually, well temperature measurements are used to determine the thermal flux of the crust. However, these measurements are scarce, not evenly distributed and are generally obtained from depths larger than one kilometer. Magnetotellurics and seismic methods only provide indirect evidence of electrical resistivity or seismic velocities, which may in turn indicate higher or lower temperatures, but do not yield absolute temperature estimates. On the other hand, magnetic data can be used to estimate the geothermal gradient, under the proper technical and geotectonic conditions previously discussed.

The geothermal gradient responds to the variation of temperature between the surface and a determined point in depth according to equation?

$$
\nabla G=\frac{\Delta T}{\Delta Z}=\frac{T_{2}-T_{1}}{Z_{2}-Z_{1}}=\frac{T_{c}-T_{\text {sur }}}{Z_{b}}
$$

where $\mathrm{T}_{\mathrm{c}}$ is Curie temperature, $\mathrm{Z}_{\mathrm{b}}$ is the depth to the base of the magnetic layer, and $T_{\text {sur }}$ is the average temperature at the surface. Many publications assume that the mean surface temperature is considered $0{ }^{\circ} \mathrm{C}$ (e.g. Tanaka et al., 1999; Selim \& Aboud 2014; Bilim et al., 2016), although other publications used local mean annual temperatures, eg.: $19{ }^{\circ} \mathrm{C}$ (Qingqing et al., 2008) or $26^{\circ} \mathrm{C}$ (Salem et al., 2017 ). Assuming that pure magnetite is the most common magnetic mineral in lower crustal rocks and has a Curie temperature of $580^{\circ} \mathrm{C}$, this last value is used as the Curie isotherm temperature. In addition, the geothermal gradient is associated with the thermal flux $q$ according to the Fourier's law: 


$$
\mathrm{q}=c_{t} \frac{\Delta T}{\Delta Z}=c_{t} \frac{T_{c}-T_{\text {sup }}}{Z_{b}}
$$

where $c_{t}$ is the thermal conductivity of the rocks. The average thermal conductivity of igneous rocks is $2.5 \mathrm{~W} / \mathrm{Km}$ and is used as standard. Although, more sophisticated equations for the calculation of thermal conductivity can be used, for example, assuming a nonlinear behavior, production of heat or non-negligible advection (Durham et al., 1987; Fox Maule et al., 2009; Guimarães et al., 2014; Mather \& Fullea, 2019, among others). As a first order approximation heat production is often disregarded, particularly in volcanic or thermal areas where its contribution can be considered negligible. However, it can be estimated in different ways. The distribution of radiogenic heat in the continental crust can be estimated by an exponential decay model with depth (e.g. Lachenbruch, 1970; Guimarães et al., 2014; Bilim et al., 2016): $A(z)=$ $A_{o} e^{-z / \delta}$ where Ao is the radiogenic heat production rate at the Earth's surface, $\mathrm{z}$ is depth, and $\delta$ is the radiogenic scaling depth. Also, heat production can be simplified as a constant function with depth: $A(z)=A_{o} \Delta z / 2$ (Andres et al., 2018). Even, Rybach and Buntebarth $(1982,1984)$ provided an approximation of heat production according to its relationship with observed seismic velocities: $\log (A)=12.6-2.1 V_{p}$. Although this requires previous knowledge of $\mathrm{Vp}$ velocities in the studied area, it can also be used to extrapolate Vp data (see Bilim et al., 2016). More sophisticated methods can also be applied (Guimaraes et al., 2014; Ravat et al., 2016); some are used to consider topography (e.g. Li et al., 2013), mantle contribution with two layers models (e.g. Andrés et al., 2018), or the influence of different geologic levels within a multilayer model (e.g. Expelbaum \& Pilchin, 2006; Salem et al., 2017). 


\section{Conclusions and further work}

Regarding the centroid method, we proved that according to the theoretical models, $Z_{t}$ must be calculated in wavenumbers larger than 0.05 or $0.1 \mathrm{rad} / \mathrm{km}$, with its upper limit being the Nyquist frequency. On the other hand, $Z_{o}$ must be calculated between wavenumbers 0 and 0.05 $\mathrm{rad} / \mathrm{km}$. For thinner sources, the interval to calculate $Z_{\mathrm{o}}$ can be extended, and $Z_{t}$ must be reduced. For very thin sources $(\Delta Z$ less than $2 \mathrm{~km}), Z_{t}$ cannot be calculated, and $Z_{b}$ can be calculated at almost all wavenumbers (see Figs 2 and 3).

In the simplified fractal method, we showed that $Z_{t}$ can be calculated using almost all the wavenumbers, except in a restricted region with wavenumbers less than $\sim 0.05 \mathrm{rad} / \mathrm{km}$. However, $Z_{0}$ can only be calculated using a restricted interval between 0 to $0.03 \mathrm{rad} / \mathrm{km}$, especially if $\Delta \mathrm{Z}$ is larger than $20 \mathrm{~km}$. For thinner bodies (less than $20 \mathrm{~km}$ ), $\mathrm{Z}_{\mathrm{o}}$ can be calculated in a wider region comparable to Zt (see Figs 8 and 9).

The spectral peak and forward modeling methods are inter-related and can be improved if used together. However, these methods depend on the presence of the spectral peak and are limited to random magnetized sources.

Multilayer interpretations should be avoided, otherwise, they should be carefully supported by theoretical and practical frameworks, since this methodology reflects statistical averages and does not separate the effects of multiple sources (except in very particular conditions). However, a multi-layer composite system can produce results that exceed the actual depth of the bodies. Consequently, those scenarios should be carefully evaluated and discussed. The use of filters must be cautious and the reasons for using them must be reported, also, when possible, comparing results obtained from unfiltered and filtered data.

Further work should address the different geological settings in which the method has been applied. We came across numerous publications where methods were ill-described, experiments badly applied, and conclusions invalid due to several mistakes made during the calculations. In such conditions it is impossible to compare results, conditions or methods (see Barr et al. 1995; Fehr et al., 2016; Crick et al., 2017; NASEM, 2019). 
Neither do we discuss different methodologies for estimating the error in the depths calculated applying the distinct spectral methods. However, it should be noted that if the mathematical conditions are not satisfied or if the conditions and methodologies applied are not reported, any error calculation is meaningless. Moreover, there are so many variables to control that it becomes very difficult to quantify the error propagation. Further studies are required to analyze how the variation of the different parameters alters the results.

We will present a continuation of this study in this respect, analyzing how the variation of some parameters and procedures affects the calculated depths.

\section{Acknowledgments}

We thank Carlos Vasquez of the Universidad de Buenos Aires and CONICET (Argentina), and Ramon Caraballo of the Universidad de la República (Uruguay) for their valuable contributions to this paper. We would like to thank Claire Bouligand and the anonymous reviewer for their contributions to improving this paper. PICT 2016/0709 partially funded this research.

\section{References}

Abbass, A. A., \& Mallam, A. 2013. Estimating the thickness of sedimentation within Lower Benue Basin and Upper Anambra Basin, Nigeria, using both spectral depth determination and source parameter imaging. ISRN Geophysics, 2013.

Abderbi, J., Khattach, D., \& Kenafi, J. 2017. Aeromagnetic contributions to the study of the Paleozoic basement structure of Southern High Plateaus (Eastern Morocco). Arab. J. Geosci, 10(19), 423.

Aboud, E,, Salem, A., \& Mekkawi, M. 2011. Curie depth map for Sinai Peninsula, Egypt deduced from the analysis of magnetic data. Tectonophysics, 506(1-4), 46-54.

Afshar, A., Norouzi, G. H., Moradzadeh, A., Riahi, M. A., \& Porkhial, S. 2017. Curie Point Depth, Geothermal Gradient and Heat-Flow Estimation and Geothermal Anomaly 
Exploration from Integrated Analysis of Aeromagnetic and Gravity Data on the Sabalan Area, NW Iran. Pure Appl. Geophys., 174(3), 1133-1152.

Agrawal, P. K., Thakur, N. K., \& Negi, J. G. 1992. MAGSAT data and Curie-depth below Deccan flood basalts (India). Pure Appl. Geophys., 138(1), 61-75.

Aliyu, A., Salako, K. A., Adewumi, T., \& Mohammed, A. 2018. Interpretation of High Resolution Aeromagnetic Data to Estimate the Curie Point Depth Isotherm of Parts of Middle Benue Trough, North-East, Nigeria. Phys. Sci. Int. J., 1-9.

Andrés, J., Marzán, I., Ayarza, P., Martí, D., Palomeras, I., Torné, M., Campbell, S. and Carbonell, R 2018. Curie point depth of the Iberian Peninsula and surrounding margins. A thermal and tectonic perspective of its evolution. J. Geophys. Res: Solid Earth, 123(3), 2049-2068.

Arkani-Hamed, J., \& Strangway, D. W. 1986. Effective magnetic susceptibility of the oceanic upper mantle derived from MAGSAT data. Geophys. Res. Lett., 13(10), 999-1002.

Astort, A., Colavitto, B., Sagripanti, L., García, H., Echaurren, A., Soler, S., F. Ruíz \& Folguera, A. 2019. Crustal and mantle structure beneath the southern Payenia Volcanic Province using gravity and magnetic data. Tectonics, 38(1), 144-158.

Ates, A., Bilim, F., \& Buyuksarac, A. 2005. Curie point depth investigation of Central Anatolia, Turkey. Pure Appl. Geophys., 162(2), 357-371.

Audet, P., \& Gosselin, J. M. 2019. Curie depth estimation from magnetic anomaly data: a reassessment using multitaper spectral analysis and Bayesian inference. Geophys. J. Int., 218(1), 494-507.

Aydemir, A., Bilim, F., Cifci, G., \& Okay, S. 2018. Modeling of the Foca-Uzunada magnetic anomaly and thermal structure in the gulf of Izmir, western Turkey. J. Asian Earth Sci., $156,288-301$.

Aydın, İ., Karat, H. İ., \& Koçak, A. 2005. Curie-point depth map of Turkey. Geophys. J. Int., 162(2), 633-640.

Aydin, I., \& Oksum, E. 2010. Exponential approach to estimate the Curie-temperature depth. J. Geophys. Eng, 7(2), 113-125. 
Azab, A. A. 2014. Agnes high, Western Desert, Egypt: A structural study in view of potential data modelling. Egypt. J. Pet., 23(2), 229-245.

Bansal, A. R., \& Dimri, V. P. 2005. Depth determination from a non-stationary magnetic profile for scaling geology. Geophys. Prospect., 53(3), 399-410.

Bansal, A. R., Gabriel, G., Dimri, V. P., \& Krawczyk, C. M. 2011. Estimation of depth to the bottom of magnetic sources by a modified centroid method for fractal distribution of sources: An application to aeromagnetic data in Germany. Geophysics, 76(3), L11-L22.

Bansal, A. R., \& Dimri, V. P. 2013. Modelling of magnetic data for scaling geology. Geophys. Prospect., 62(2), 385-396.

Bansal, A. R., Anand, S. P., Rajaram, M., Rao, V. K., \& Dimri, V. P. 2013. Depth to the bottom of magnetic sources (DBMS) from aeromagnetic data of Central India using modified centroid method for fractal distribution of sources. Tectonophysics, 603, 155-161.

Baranov, V. 1957. A new method for interpretation of aeromagnetic maps: pseudo-gravimetric anomalies. Geophysics, 22(2), 359-382.

Baranov, V., Naudy, H.1964. Numerical calculation of the formula of reduction to the magnetic pole. Geophysics 29:67-79

Barr, R. S., Golden, B. L., Kelly, J. P., Resende, M.G., \& Stewart, W. R. 1995. Designing and reporting on computational experiments with heuristic methods. J. Heuristics, 1(1), 932.

Bektaş, Ö., Ravat, D., Büyüksaraç, A., Bilim, F., \& Ateş, A. 2007. Regional geothermal characterisation of East Anatolia from aeromagnetic, heat flow and gravity data. Pure Appl. Geophys., 164(5), 975-998.

Bello, R., Ofoha, C. C., \& Wehiuzo, N. 2017. Geothermal gradient, Curie point depth and heat flow determination of some parts of lower Benue trough and Anambra basin, Nigeria, Using High Resolution Aeromagnetic Data. Phys. Sci. Int. J., 1-11.

Beardsmore, G. R. \& Cull, J. P. 2001. Crustal heat flow: a guide to measurement and modelling. Cambridge University Press. 324 pp. 
Bhattacharyya, B. K., \& Leu, L. K. 1975a. Analysis of magnetic anomalies over Yellowstone National Park: mapping of Curie point isothermal surface for geothermal reconnaissance. J. Geophys. Res, 80(32), 4461-4465.

Bhattacharyya, B. K., \& Leu, L. K. 1975b. Spectral analysis of gravity and magnetic anomalies due to two-dimensional structures. Geophysics, 40(6), 993-1013.

Bhattacharyya, B. K., \& Leu, L. K. 1977. Spectral analysis of gravity and magnetic anomalies due to rectangular prismatic bodies. Geophysics, 42(1), 41-50.

Bilim, F. 2011. Investigation of the Galatian volcanic complex in the northern central Turkey using potential field data. Phys. Earth Planet. Inter, 185(1-2), 36-43.

Bilim, F., Akay, T., Aydemir, A., \& Kosaroglu, S. 2016. Curie point depth, heat-flow and radiogenic heat production deduced from the spectral analysis of the aeromagnetic data for geothermal investigation on the Menderes Massif and the Aegean Region, western Turkey. Geothermics, 60, 44-57.

Blakely, R. J. 1996. Potential theory in gravity and magnetic applications. Cambridge university press. $441 \mathrm{p}$.

Bonde, D. S, Udensi E. E, Rai J. K. 2014 Spectral Depth Analysis of Sokoto Basin. IOSR J. Appl. Phys., 6, 15-21.

Bouligand, C., Glen, J. M., \& Blakely, R. J. 2009. Mapping Curie temperature depth in the western United States with a fractal model for crustal magnetization. J. Geophys. Res: Solid Earth, 114(B11).

Brigham, E. O. 1988. The fast Fourier transform and its applications (Vol. 448). Englewood Cliffs, NJ: prentice Hall. 448 p.

Brown, S. R. \& Scholz, C. H. 1985. Broad bandwidth study of the topography of natural rock surfaces, J. Geophys. Res., 90,12 575-12 582.

Bulina, L. V. 1961. The use of airborne magnetic prospecting data in deep-seated structure of the Earth's crust within the Siberian platform. Sovetskaya Geologiya, 5, 134-138.

Burger, W., \& Burge, M. J. 2016. Digital image processing: an algorithmic introduction using Java. Springer. $811 \mathrm{p}$. 
Chiozzi, P., Matsushima, J., Okubo, Y., Pasquale, V., \& Verdoya, M. 2005. Curie-point depth from spectral analysis of magnetic data in central-southern Europe. Phys. Earth Planet. Inter, 152(4), 267-276.

Chopping, R., \& Kennett, B. 2013. The Curie depth of Australia, and its uncertainty. ASEG Extended Abstracts, 2013(1), 1-3.

Connard, G., Couch, R., \& Gemperle, M. 1983. Analysis of aeromagnetic measurements from the Cascade Range in central Oregon. Geophysics, 48(3), 376-390.

Counil, J. L., Achache, J., \& Galdeano, A. 1989. Long-wavelength magnetic anomalies in the Caribbean: Plate boundaries and allochthonous continental blocks. J. Geophys. Res: Solid Earth, 94(B6), 7419-7431.

Crick, T.; Hall, B.; Ishtiaq, S. 2017 Reproducibility in Research: Systems, Infrastructure, Culture. J. Open Res. Softw., 5, 32.

De Ritis, R., Ravat, D., Ventura, G., \& Chiappini, M. 2013. Curie isotherm depth from aeromagnetic data constraining shallow heat source depths in the central Aeolian Ridge (Southern Tyrrhenian Sea, Italy). Bulletin of Volcanology, 75(4), 710.

Dentith, M., Mudge, S., 2014. Geophysics for the Mineral Exploration Geoscientist. Cambridge University Press. 438pp.

Dolmaz, M. N., Hisarli, Z. M., Ustaömer, T., \& Orbay, N. 2005a. Curie point depths based on spectrum analysis of aeromagnetic data, West Anatolian extensional province, Turkey. Pure Appl. Geophys., 162(3), 571-590.

Dolmaz, M. N., Ustaömer, T., Hisarli, Z. M., \& Orbay, N. 2005b. Curie point depth variations to infer thermal structure of the crust at the African-Eurasian convergence zone, SW Turkey. Earth, Planets and Space, 57(5), 373-383.

Dunlop, D. .., Özdemir, Ö., \& Costanzo-Alvarez, V. 2010. Magnetic properties of rocks of the Kapuskasing uplift (Ontario, Canada) and origin of long-wavelength magnetic anomalies. Geophys. J. Int., 183(2), 645-658.

Dunlop, D. J. 2014. High-temperature susceptibility of magnetite: a new pseudo-single-domain effect. Geophys. J. Int., 199(2), 707-716. 
Durham, W. B., Mirkovich, V. V., and Heard, H. C., 1987 Thermal diffusivity of igneous rocks at elevated pressure and temperature, J. Geophys. Res.-Sol. Ea., 92, 11615-11634, https://doi.org/10.1029/JB092iB11p11615, 1987.

Ebbing, J., Gernigon, L., Pascal, C., Olesen, O., \& Osmundsen, P. T. 2009. A discussion of structural and thermal control of magnetic anomalies on the mid-Norwegian margin. Geophys. Prospect., 57(4), 665-681.

Elbarbary, S., Zaher, M. A., Mesbah, H., El-Shahat, A., \& Embaby, A. 2018. Curie point depth, heat flow and geothermal gradient maps of Egypt deduced from aeromagnetic data. Renewable and Sustainable Energy Reviews, 91, 620-629.

Elitok, Ö., \& Dolmaz, M. N. 2008. Mantle flow-induced crustal thinning in the area between the easternmost part of the Anatolian plate and the Arabian Foreland (E Turkey) deduced from the geological and geophysical data. Gondwana Res., 13(3), 302-318.

Eppelbaum, L. V., \& Pilchin, A. N. 2006. Methodology of Curie discontinuity map development for regions with low thermal characteristics: an example from Israel. Earth Planet. Sci. Lett., 243(3-4), 536-551.

Espinosa-Cardeña, J. M., \& Campos-Enriquez, J. O. 2008. Curie point depth from spectral analysis of aeromagnetic data from Cerro Prieto geothermal area, Baja California, Mexico. J. Volcanol. Geotherm. Res., 176(4), 601-609.

Fedi, M., Quarta, T., \& De Santis, A. 1997. Inherent power-law behavior of magnetic field power spectra from a Spector and Grant ensemble. Geophysics, 62(4), 1143-1150.

Fehr, J., Heiland J., Himpe, C., Saak, J., 2016. Best practices for replicability, reproducibility and reusability of computer-based experiments exemplified by model reduction software. AIMS Mathematics.;1(3):261-281. doi: 10.3934/Math.2016.3.261.

Ferré, E. C., Friedman, S. A., Martín-Hernández, F., Feinberg, J. M., Conder, J. A., \& Ionov, D. A. 2013. The magnetism of mantle xenoliths and potential implications for sub-Moho magnetic sources. Geophys. Res. Lett., 40(1), 105-110. 
Ferre, E. C., Friedman, S. A., Martin-Hernandez, F., Feinberg, J. M., Till, J. L., Ionov, D. A., \& Conder, J. A. 2014. Eight good reasons why the uppermost mantle could be magnetic. Tectonophysics, 624, 3-14.

Fox Maule, C., Purucker, M. E., \& Olsen, N. 2009. Inferring magnetic crustal thickness and geothermal heat flux from crustal magnetic field models. Estimating the geothermal heat flux beneath the Greenland ice sheet. Danish Climate Centre Report, 9(09).

Friedman, S. A., Feinberg, J. M., Ferré, E. C., Demory, F., Martín-Hernández, F., Conder, J. A., \& Rochette, P. 2014. Craton vs. rift uppermost mantle contributions to magnetic anomalies in the United States interior. Tectonophysics, 624, 15-23.

Frost, B. R., \& Shive, P. N. 1986. Magnetic mineralogy of the lower continental crust. J. Geophys. Res: Solid Earth, 91(B6), 6513-6521.

García-Abdeslem, J., \& Ness, G. E. 1994. Inversion of the power spectrum from magnetic anomalies. Geophysics, 59(3), 391-401.

Githiri, J. G., Patel, J. P., Barongo, J. O., \& Karanja, P. K. 2012. Spectral analysis of ground magnetic data in Magadi area, Southern Kenya Rift. Tanzania Journal of Science, 38(1), $1-14$.

Gomes, D. G. C., Couto, M. A., Vieira, V. S., Silva, M. A., Drews, M. G. P., \& Novais, L. C. C. 2015. Compartimentação e caracterização do arcabouço estrutural dos corpos magnéticos através da análise do espectro de potência para o estado do Espírito Santo.IX International Symposium on Tectonics. 195-198.

Gregotski, M. E., Jensen, O., \& Arkani-Hamed, J. 1991. Fractal stochastic modeling of aeromagnetic data. Geophysics, 56(11), 1706-1715.

Guimarães, S. N. P., Ravat, D., \& Hamza, V. M. 2014. Combined use of the centroid and matched filtering spectral magnetic methods in determining thermomagnetic characteristics of the crust in the structural provinces of Central Brazil. Tectonophysics, $624,87-99$.

Haggerty, S. E. 1978. Mineralogical contraints on Curie isotherms in deep crustal magnetic anomalies. Geophys. Res. Lett., 5(2), 105-108. 
Hall, D. H. 1968. Regional magnetic anomalies, magnetic units, and crustal structure in the Kenora District of Ontario. Can. J. Earth Sci., 5(5), 1277-1296.

Harrison, C. G. A., \& Carle, H. M. 1981. Intermediate wavelength magnetic anomalies over ocean basins. J. Geophys. Res: Solid Earth, 86(B12), 11585-11599.

Harrouchi, L., Hamoudi, M., Bendaoud, A., \& Beguiret, L. 2016. Application of 3D Euler deconvolution and improved tilt angle to the aeromagnetic data of In Ouzzal terrane, western Hoggar, Algeria. Arab. J. Geosci., 9(7), 508.

Hewett, T. A. 1986. Fractal distributions of reservoir heterogeneity and their influence on fluid transport. In SPE Annual Technical Conference and Exhibition. Soc. Pet. Eng. J..

Hildenbrand, T. G., Rosenbaum, J. G., \& Kauahikaua, J. P. 1993. Aeromagnetic study of the island of Hawaii. J. Geophys. Res: Solid Earth, 98(B3), 4099-4119.

Hinze, W., Frese, R., \& Saad, A., 2012. Gravity and magnetic exploration, Principles, practices and applications. Cambridge University Press, pp. 515.

Hirata, T., Satoh, T., \& Ito, K. 1987. Fractal structure of spatial distribution of microfracturing in rock. Geophys. J. Int., 90(2), 369-374. doi:10.1111/j.1365-246x.1987.tb00732.x

Hisarli, Z. M., Dolmaz, M. N., Okyar, M., Etiz, A., \& Orbay, N. 2012. Investigation into regional thermal structure of the Thrace Region, NW Turkey, from aeromagnetic and borehole data. Stud. Geophys Geod. a, 56(1), 269-291.

Hopkinson, J. 1889. Magnetic and other physical properties of iron at a high temperature. Philos Trans. R. Soc. Lond..(A.), (180), 443-465.

Hosken, J. W. J. 1980. A stochastic model of seismic reflections: Presented at the 50th Ann. Internat. Mtg., Soc. Expl. Geophys.

Hsieh, H. H., Chen, C. H., Lin, P. Y., \& Yen, H. Y. 2014. Curie point depth from spectral analysis of magnetic data in Taiwan. J. Asian Earth Sci., 90, 26-33.

Hunt, C. P., Moskowitz, B. M., \& Banerjee, S. K. 1995. Magnetic properties of rocks and minerals. Rock physics and phase relations: A handbook of physical constants, 3, 189204. 
Hussein, M., Mickus, K., \& Serpa, L. F. 2013. Curie point depth estimates from aeromagnetic data from Death Valley and surrounding regions, California. Pure Appl. Geophys., $170(4), 617-632$.

Idárraga-García, J., \& Vargas, C. A. 2018. Depth to the bottom of magnetic layer in South America and its relationship to Curie isotherm, Moho depth and seismicity behavior. Geod. Geodyn., 9(1), 93-107.

Ikumbur E.B., Onwuemesi A.G., Anakwuba E.K., Chinwuko A.I., Usman A.O., \& Okonkwo C.C. 2013. Spectral analysis of aeromagnetic data over part of the Southern Bida basin, West-Central Nigeria. Int J Fundamental Phys Sci 3: 27-31.

Kiss, J., Szarka, L., \& Prácser, E. 2005. Second-order magnetic phase transition in the Earth. Geophys. Res. Lett., 32(24).

Kletetschka, G., Wasilewski, P. J., \& Taylor, P. T. 2002. The role of hematite-ilmenite solid solution in the production of magnetic anomalies in ground-and satellite-based data. Tectonophysics, 347(1-3), 167-177.

Lachenbruch, A.H., 1970. Crustal temperature and heat production: implication ofthe linear heat flow relationship. J. Geophys. Res. 75, 3291-3300

Langel, R. A., \& Hinze, W. J. 1998. The magnetic field of the Earth's lithosphere: The satellite perspective. Cambridge University Press.

Leseane, K., Atekwana, E. A., Mickus, K. L., Abdelsalam, M. G., Shemang, E. M., \& Atekwana, E. A. 2015. Thermal perturbations beneath the incipient Okavango Rift zone, northwest Botswana. J. Geophys. Res: Solid Earth, 120(2), 1210-1228.

Li, T., \& Eaton, D. W. 2005. On the roles of magnetization and topography in the scaling behaviour of magnetic-anomaly fields. Geophys. J. Int., 160(1), 46-54.

Li C.F., Wang, J., Lin, J., \& Wang, T. 2013. Thermal evolution of the North Atlantic lithosphere: new constraints from magnetic anomaly inversion with a fractal magnetization model. Geochem Geophys Geosyst 14(12): 5078-5105. https ://doi.org/10.1002/2013G C0048 96 
Li, C.F., Lu, Y., \& Wang, J. 2017. A global reference model of Curiepoint depths based on EMAG2. Sci Rep 7:45129. https ://doi.org/10.1038/srep4 5129.

Mahmood, F., Toots, M., Öfverstedt, L. G., \& Skoglund, U. 2015. 2D discrete Fourier transform with simultaneous edge artifact removal for real-time applications. In 2015 International Conference on Field Programmable Technology (FPT) (pp. 236-239). IEEE.

Mandelbrot, B. B. 1983. The fractal geometry of nature. New York, WH Freeman and Co., 495

p.

Manea, M., \& Manea, V. C. 2011. Curie point depth estimates and correlation with subduction in Mexico. Pure Appl. Geophys., 168(8-9), 1489-1499.

Mather, B., \& Fullea, J. 2019. Constraining the geotherm beneath the British Isles from Bayesian inversion of Curie depth: integrated modelling of magnetic, geothermal, and seismic data. Solid Earth, 10(3), 839-850.

Maus, S., \& Dimri, V. 1995. Potential field power spectrum inversion for scaling geology. J. Geophys. Res: Solid Earth, 100(B7), 12605-12616.

Maus, S., \& Dimri, V. 1996. Depth estimation from the scaling power spectrum of potential fields?. Geophys. J. Int., 124(1), 113-120.

Maus, S., Gordon, D., \& Fairhead, D. 1997. Curie-temperature depth estimation using a selfsimilar magnetization model. Geophys. J. Int., 129(1), 163-168.

McEnroe, S. A., Langenhorst, F., Robinson, P., Bromiley, G. D., \& Shaw, C. S. J. 2004. What is magnetic in the lower crust? Earth Planet. Sci. Lett., 226(1-2), 175-192. doi:10.1016/j.eps1.2004.07.020

Mohr, P. J., \& Phillips, W. D. 2014. Dimensionless units in the SI. Metrologia, 52(1), 40.

Moisan, L. 2011. Periodic plus smooth image decomposition. J. Math. Imaging. Vis., 39(2), $161-179$.

Mono, J. A., Ndougsa-Mbarga, T., Tarek, Y., Ngoh, J. D., \& Amougou, O. U. I. O. 2018. Estimation of Curie-point depths, geothermal gradients and near-surface heat flow from spectral analysis of aeromagnetic data in the Loum-Minta area (Centre-East Cameroon). Egypt. J. Pet., 27(4), 1291-1299. 
Moraes Rocha, L. G., Pires, A. C. B., Carmelo, A. C., \& Oksum, E. 2015. Curie surface of the alkaline provinces of Goiás (GAP) and Alto Paranaíba (APAP), central Brazil. J. Volcanol. Geotherm. Res., 297, 28-38.

Mousa, A., Mickus, K., \& Al-Rahim, A. 2017. The thickness of cover sequences in the Western Desert of Iraq from a power spectrum analysis of gravity and magnetic data. J. Asian Earth Sci., 138, 230-245.

(NASEM) National Academies of Sciences, Engineering, and Medicine 2019. Reproducibility and Replicability in Science. Washington, DC: The National Academies Press. https://doi.org/10.17226/25303.

Nwankwo, L. I. 2015. Estimation of depths to the bottom of magnetic sources and ensuing, geothermal parameters from aeromagnetic data of Upper Sokoto Basin, Nigeria. Geothermics, 54, 76-81.

Nwobgo, P.O., 1998. Spectral prediction of magnetic source depths from simplenumerical models. Comput. Geosci.: 24:847-852.Okubo, Y., Graf, R. J,, Hansen, R. O., Ogawa, K., \& Tsu, H. 1985. Curie point depths of the island of Kyushu and surrounding areas, Japan. Geophysics, 50(3), 481-494.

Okubo, Y., \& Matsunaga, T. 1994. Curie point depth in northeast Japan and its correlation with regional thermal structure and seismicity. J. Geophys. Res: Solid Earth, 99(B11), 22363-22371.

Phillips, J. D. 2001. Designing matched bandpass and azimuthal filters for the separation of potential-field anomalies by source region and source type. ASEG Extended Abstracts, 2001(1), 1-4.

Pilkington, M., \& Todoeschuck, J. P. 1993. Fractal magnetization of continental crust. Geophys. Res. Lett., 20(7), 627-630.

Pilkington, M., Gregotski, M. E., \& Todoeschuck, J. P. 1994. Using fractal crustal magnetization models in magnetic interpretation 1. Geophys. Prospect., 42(6), 677-692. 
Qingqing, Q., Qingsheng, L., Ning, Q., Yuanyuan, F., Sutao, Z., Yao, W., Tao, Y. \& Zhenmin, J. 2008. Investigation of Curie point depth in Sulu ultrahigh-pressure metamorphic belt, eastern China. J. China Univ. Geosci., 19(3), 282-291

Quintero, W., Campos-Enríquez, O., \& Hernández, O. 2019. Curie point depth, thermal gradient, and heat flow in the Colombian Caribbean (northwestern South America). Geothermal Energy, 7(1), 2.

Rajaram, M., Anand, S. P., Hemant, K., \& Purucker, M. E. 2009. Curie isotherm map of Indian subcontinent from satellite and aeromagnetic data. Earth Planet. Sci. Lett., 281(3-4), $147-158$.

Ravat, D., Pignatelli, A., Nicolosi, I., \& Chiappini, M. 2007. A study of spectral methods of estimating the depth to the bottom of magnetic sources from near-surface magnetic anomaly data. Geophys. J. Int., 169(2), 421-434.

Ravat, D., Morgan, P., \& Lowry, A.R. (016. Geotherms from the temperature-depthconstrained solutions of 1-D steady-state heat-flow equation: Geosphere, 12(4): 11871197, doi:10.1130/GES01235.1.

Ridsdill-Smith, T. A. 1998. Separation filtering of aeromagnetic data using filter-banks. Explor. Geophys., 29(4), 577-583.

Roest, W.R., \& Pilkington, M., 1993. Identifying remanent magnetization effects in magnetic data. Geophysics, 58(5), 653-659.

Rozimant, K., Büyüksaraç, A., \& Bektaş, Ö. 2009. Interpretation of magnetic anomalies and estimation of depth of magnetic crust in Slovakia. Pure Appl. Geophys., 166(3), 471484.

Rybach, L., \& Buntebarth, G., 1982. Relationship between the petrophysicalproperties density, seismic velocity, heat generation and mineralogicalconstitution. Earth Planet. Sci. Lett. $57,367-376$.

Rybach, L., \& Buntebarth, G., 1984. The variation of heat generation, density andseismic velocity with rock type in the continental crust. Tectonophysics 103,309-344. 
Saad, A. H. 1969. Magnetic properties of ultramafic rocks from Red Mountain, California. Geophysics, 34(6), 974-987.

Saibi, H., Aboud, E., \& Azizi, M. 2015. Curie point depth map for western Afghanistan deduced from the analysis of aeromagnetic data. In World Geothermal Congress, Melbourne, Australia. 1-12

Salazar, J. M., Vargas, C. A., \& Leon, H. 2017. Curie point depth in the SW Caribbean using the radially averaged spectra of magnetic anomalies. Tectonophysics, 694, 400-413.

Saleh, S., Salk, M., \& Pamukçu, O. 2013. Estimating Curie point depth and heat flow map for northern Red Sea rift of Egypt and its surroundings, from aeromagnetic data. Pure Appl. Geophys., 170(5), 863-885.

Salem, A., Green, C., Ravat, D. Singh K.H., East P., Fairhead J.D., Mogren, S. \& Biegert E. 2014. "Depth to Curie temperature across the central Red Sea from magnetic data using the de-fractal method." Tectonophysics 624: 75-86.

Salem, A., Hussein, W., Ion, D., Bruno, P. S., Wu, S., \& Borsato, R. 2017. Predicting Heat Flow and Determining Crustal Type Based on Integrated Interpretation of Seismic, Gravity and Magnetic Data in the Offshore Jazan Area, Southern Red Sea. In SPE Middle East Oil \& Gas Show and Conference. Soc. Pet. Eng. J..

Selim, E. I. \& Aboud, E. 2014. Application of spectral analysis technique on ground magnetic data to calculate the Curie depth point of the eastern shore of the Gulf of Suez, Egypt. Arab. J. Geosci., 7(5), 1749-1762.

Scholz, C. H., \& Aviles, C. A. 1986. The fractal geometry of faults and faulting. Earthquake Source Mechanics, 37, 147-155.

Silva J B. 1986. Reduction to the pole as an inverse problem and its application to low-latitude anomalies, Geophysics, vol. 51 (pg. 369-382)https://doi.org/10.1190/1.1442096

Spector, A., \& Grant, F. S. 1970. Statistical models for interpreting aeromagnetic data. Geophysics, 35(2), 293-302.

Stampolidis, A., \& Tsokas, G. N. 2002. Curie point depths of Macedonia and Thrace, N. Greece. Pure Appl. Geophys., 159(11-12), 2659-2671. 
Tanaka, A., Okubo, Y., \& Matsubayashi, O. 1999. Curie point depth based on spectrum analysis of the magnetic anomaly data in East and Southeast Asia. Tectonophysics, 306(3-4), 461-470.

Tanaka, A., \& Ishikawa, Y. 2005. Crustal thermal regime inferred from magnetic anomaly data and its relationship to seismogenic layer thickness: The Japanese islands case study. Phys. Earth Planet. Inter, 152(4), 257-266.

Tanaka, A. 2017. Global centroid distribution of magnetized layer from world digital magnetic anomaly map. Tectonics, 36(12), 3248-3253.

Todoeschuck, J. P., Pilkington, M., \& Gregotski, M. E. 1992. If geology is fractal, what do we do next?. The Leading Edge, 11(10), 29-35.

Treitel, S., Clement, W. G., \& Kaul, R. K. 1971. The spectral determination of depths to buried magnetic basement rocks. Geophys. J. Int., 24(4), 415-428.

Trifonova, P., Zhelev, Z., Petrova, T., \& Bojadgieva, K. 2009. Curie point depths of Bulgarian territory inferred from geomagnetic observations and its correlation with regional thermal structure and seismicity. Tectonophysics, 473(3-4), 362-374.

Tselentis, G. A. 1991. An attempt to define Curie point depths in Greece from aeromagnetic and heat flow data. Pure Appl. Geophys., 136(1), 87-101.

Tsokas, G. N., Hansen, R. O., \& Fytikas, M. 1998. Curie point depth of the island of Crete (Greece). Pure Appl. Geophys., 152(4), 747-757.

Tsvetkov, Y. P., Novikov, K. Y., Ivanov, A. A., \& Brekhov, O. M. 2018. Sources of the lithosphere magnetic field based on magnetic data obtained at different heights. Earth, Planets Space, 70(1), 183.

Twinkle, D., Rao, G. S., Radhakrishna, M., \& Murthy, K. S. R. 2016. Crustal structure and rift tectonics across the Cauvery-Palar basin, Eastern Continental Margin of India based on seismic and potential field modelling. J. Earth Syst. Sci., 125(2), 329-342.

Usman, A. O., Ezeh, C. C., \& Chinwuko, A. I. 2018 Integration of Aeromagnetic Interpretation and Induced Polarization Methods in Delineating Mineral Deposits and Basement 
Configuration within Southern Bida Basin, North-West Nigeria. J. Geol. Geophys 7: 6971. doi: $10.4172 / 2381-8719.1000449$

Usman, A. O., Ezeh, C. C., Omali, A. O., \& Chinwuko, A. I. 2019. Integration of Aeromagnetic Interpretation and Induced Polarization Methods in Delineating Mineral Deposits and Basement Configuration Within Southern Bida Basin, North-West Nigeria. In On Significant Applications of Geophysical Methods (pp. 69-71). Springer, Cham.

Vargas, C. A., Idarraga-Garcia, J., \& Salazar, J. M. 2015. Curie point depths in northwestern South America and the southwestern Caribbean Sea. Memoir 108: Petroleum Geology and Potential of the Colombian Caribbean Margin. pp. 179-200

Wang, M., \& Liu, Z. 2018. The effects of anisotropy of marine magnetic anomalies on the Curie point depth estimates from spectral analysis. Acta Geophysica, 66(5), 1019-1030.

Wasilewski, P. J., Thomas, H. H., \& Mayhew, M. A. 1979. The Moho as a magnetic boundary. Geophys. Res. Lett., 6(7), 541-544.

Wasilewski, P. J., \& Mayhew, M. A. 1992. The Moho as a magnetic boundary revisited. Geophys. Res. Lett., 19(22), 2259-2262.

Xi, Y., Wang, Y., Hu, X., Liu, S., Zhao, Y., \& Liu, T. 2015. Geothermal structure revealed by Curie isotherm surface in Guangdong province. In International Workshop and Gravity, Electrical \& Magnetic Methods and their/Applications, Chenghu, China, 19-22 April 2015 (pp. 189-192). Society of Exploration Geophysicists and and Chinese Geophysical Society.

Xiong, S.Q., Yang, H., Díng, Y.Y., Li, Z.K., 2016. Characteristics of Chinese continent Curie point isotherm. Chin. J. Geophys. 59, 643-657.

Zaher, M. A., Saibi, H., Mansour, K., Khalil, A., \& Soliman, M. 2018. Geothermal exploration using airborne gravity and magnetic data at Siwa Oasis, Western Desert, Egypt. Renew. Sustain. Energy Rev., 82, 3824-3832.

Zhang, Q., Zhang, Y. T., Yin, G., \& Li, Z. N. 2018. An improved frequency-domain algorithm for stable reduction to the pole at low latitudes. J. Geophys. Eng., 15(4), 1767-1782. doi:10.1088/1742-2140/aaa227 
Zhou, S., \& Thybo, H. 1998. Power spectra analysis of aeromagnetic data and KTB susceptibility logs, and their implication for fractal behavior of crustal magnetization. Pure Appl. Geophys., 151(1), 147-159. 
Table 1.- Parameters used by different authors in the calculation of $Z_{o}$ and $Z_{t}$. Asterisk (*) indicates data ranges that were not specified but were deduced from figures; these values represent maximum and minimum observed wavenumber ranges in which $Z_{t}$ or $Z_{o}$ were calculated; (notice that, real ranges may be even wider). Values indicated with "fixed", are strictly calculated in the entire interval. Notice that only few authors indicate their calculation intervals or use fixed intervals. Colors indicate if wavenumber ranges are mathematically appropriate (green), inappropriate (yellow), very inappropriate (red). (?) Indicates when values are doubtful because the units, scales and/or captions are inconsistent or unclear.

\begin{tabular}{|c|c|c|c|c|c|}
\hline Authors & $\begin{array}{l}\text { Ranges in } \\
\text { which Zo is } \\
\text { calculated } \\
(\mathrm{rad} / \mathrm{km})\end{array}$ & $\begin{array}{l}\text { Ranges in } \\
\text { which } \mathbf{Z t} \text { is } \\
\text { calculated } \\
(\mathrm{rad} / \mathrm{km})\end{array}$ & $\begin{array}{l}\text { Original } \\
\text { units }\end{array}$ & Window Size & $\begin{array}{l}\text { Windows } \\
\text { Overlaping }\end{array}$ \\
\hline $\begin{array}{l}\text { Recommended in this } \\
\text { paper }\end{array}$ & $\sim 0-0.05$ & $0.1-0.5$ & $\mathrm{rad} / \mathrm{km}$ & - & \\
\hline Abbass \& Mallam (2013) & - & $\begin{array}{l}\sim 0-1.5 \& \\
15-25^{*}\end{array}$ & cycle $/ \mathrm{km}$ & $\sim 13 \times 13 \mathrm{~km}$ & $0 \%$ \\
\hline Abdel Zaher et al. (2018) & $\sim 0$ to $0.9^{*}$ & $\sim 0$ to $0.9^{*}$ & $1 / \mathrm{km}$ & $70 \times 70 \mathrm{~km}$ & unknown \\
\hline Abderbi et al. (2017) & - & $\sim 0$ to $0.003^{*}$ & cycle/m & $\begin{array}{l}\sim 20 \mathrm{~km} \\
\text { profiles }\end{array}$ & - \\
\hline Aboud et al. (2011) & $\sim 0$ to $2.5^{*}$ & $\sim 3$ to $6^{*}$ & cycle $/ \mathrm{km}$ & $300 \times 300 \mathrm{~km}$ & \\
\hline Afshar et al. (2016) & $\sim 0$ to $0.6^{*}$ & $\sim 0.6$ to $1.8^{*}$ & $1 / \mathrm{km}(?)$ & $100 \times 100 \mathrm{~km}$ & \\
\hline Agrawal et al. (1992) & - & $\sim 0$ to 25 & cycle $/ \mathrm{km}$ & $\begin{array}{l}1300 \mathrm{~km} \\
\text { profiles }\end{array}$ & - \\
\hline Aliyu et al. (2018) & $\sim 0$ to $12 *(?)$ & $\sim 6$ to $25^{*}(?)$ & cycle $/ \mathrm{km}$ & $\begin{array}{l}55 \times 55 \mathrm{~km} \\
\& \quad 110 \\
\times 110 \mathrm{~km} \\
\end{array}$ & unknown \\
\hline Andrés et al. (2018) & $\sim 0$ to $0.1 *$ & $\sim 2$ to $3 *$ & $1 / \mathrm{km}$ & $\begin{array}{l}150 \times 150 \mathrm{~km} \\
200 \times 200 \mathrm{~km}\end{array}$ & $\sim 33 \%$ \\
\hline Astort et al. (2019) & unknown & unknown & - & unknown & unknown \\
\hline Ates et al. (2005) & $\sim 0$ to $0.04 *$ & $\sim 0$ to $0.04 *$ & $\mathrm{rad} / \mathrm{km}$ & $150 \times 150 \mathrm{~km}$ & $\sim 33 \%$ \\
\hline Aydın et al. (2005) & $\sim 0$ to $0.5^{*}$ & $\sim 0.5$ to $1^{*}$ & $\mathrm{rad} / \mathrm{km}$ & $128 \times 128 \mathrm{~km}$ & $50 \%$ \\
\hline Aydın and Oksum (2010) & $\sim 0.05$ to $0.5^{*}$ & $\sim 0.2$ to $2^{*}$ & $\mathrm{rad} / \mathrm{km}$ & $150 \times 150 \mathrm{~km}$ & $\sim 33 \%$ \\
\hline Azab (2014) & unknown & unknown & - & profiles & - \\
\hline Bansal et al. (2011) & $\sim 0$ to 0.2 & $\sim 0$ to 0.4 & $\mathrm{rad} / \mathrm{km}$ & $200 \times 200 \mathrm{~km}$ & - \\
\hline Bansal \& Dimri (2013) & - & $\sim 0$ to 18 & cycle $/ \mathrm{km}$ & $200 \times 200 \mathrm{~km}$ & - \\
\hline Bansal et al. (2013) & $\sim 0$ to $0.2^{*}$ & $\sim 0$ to $0.7^{*}$ & $\mathrm{rad} / \mathrm{km}$ & $200 \times 200 \mathrm{~km}$ & $50 \%$ \\
\hline $\operatorname{Bilim}(2011)$ & $\sim 0$ to $0.05^{*}$ & $\begin{array}{l}\sim 0.04 \text { to } \\
0.09 *\end{array}$ & $\mathrm{rad} / \mathrm{km}(?)$ & unknown & unknown \\
\hline Bilim et al. (2016) & $\sim 0.02$ to $0.07 *$ & $\begin{array}{l}\sim 0.07 \text { to } \\
0.15^{*}\end{array}$ & $\mathrm{rad} / \mathrm{km}$ & $70 \times 70 \mathrm{~km}$ & $\sim 50 \% *$ \\
\hline Chiozzi et al. (2005) & $0.03-0.3$ fixed & $\begin{array}{l}0.3-0.6 \\
\text { fixed }\end{array}$ & $1 / \mathrm{km}$ & $320 \times 320 \mathrm{~km}$ & $\sim 17 \%$ \\
\hline Connard et al. (1983) & - & $\sim 0$ to $6^{*}$ & cycle $/ \mathrm{km}$ & $\sim 60 \times 60 \mathrm{~km}$ & $50 \%$ \\
\hline Dolmaz et al. (2005a) & $\sim 0$ to $0.4^{*}$ & $\sim 0.4$ to $0.8^{*}$ & $\mathrm{rad} / \mathrm{km}(?)$ & $90 \times 90 \mathrm{~km}$ & unknown \\
\hline Dolmaz et al. (2005b) & $\sim 0$ to $0.25^{*}$ & $\sim 0.25$ to $0.7^{*}$ & $\mathrm{rad} / \mathrm{km}$ & $90 \times 90 \mathrm{~km}$ & $50 \%$ \\
\hline
\end{tabular}




\begin{tabular}{|c|c|c|c|c|c|}
\hline Ebbing et al. (2009) & $\sim 0$ to $0.3 *$ & $\sim 0$ to $1.2 *$ & $1 / \mathrm{km}$ & $\begin{array}{l}250 \times 250 \mathrm{~km} \\
475 \times 475 \mathrm{~km}\end{array}$ & uneven \\
\hline Elbarbary et al. (2018) & $\sim 0$ to $0.3^{*}$ & $\sim 0$ to $0.3^{*}$ & $1 / \mathrm{km}$ & $293 \times 278 \mathrm{~km}$ & unknown \\
\hline Elitok \& Dolmaz (2008) & unknown & unknown & - & $\begin{array}{l}90 \times 90 \mathrm{~km} \\
160 \times 160 \mathrm{~km}\end{array}$ & $\begin{array}{l}50 \% \\
78 \% \\
\end{array}$ \\
\hline $\begin{array}{l}\text { Espinosa \& Campos } \\
\text { (2008) }\end{array}$ & $\sim 0$ to $0.6^{*}$ & $\sim 0$ to $1.2 *$ & $1 / \mathrm{km}$ & $\sim 60 \times 60 \mathrm{~km}$ & - \\
\hline Gailler et al. (2016) & $\sim 0$ to $0.6^{*}$ & $\sim 0.6$ to $1.8^{*}$ & $\mathrm{rad} / \mathrm{km}$ & 20 to $240 \mathrm{~km}$ & $50 \%$ \\
\hline Githiri et al. (2012) & $\sim 0$ to $3^{*}$ & $\sim 2$ to $12 *$ & $\mathrm{rad} / \mathrm{km}(?)$ & $\begin{array}{l}\text { uneven } \\
\text { profiles }\end{array}$ & - \\
\hline \multirow{3}{*}{ Guimaraes et al (2014) } & $\sim 0.03$ to $0.7^{*}$ & $\sim 0.03$ to $0.7^{*}$ & \multirow{3}{*}{ cycle/m } & \multirow{3}{*}{$\begin{array}{l}200 \times 200 \mathrm{~km} \\
300 \times 300 \mathrm{~km}\end{array}$} & \multirow{3}{*}{-} \\
\hline & $\sim 0.4$ to $0.8^{*}$ & $\sim 0.4$ to $0.8^{*}$ & & & \\
\hline & $\sim 7.8$ to $25^{*}$ & $\sim 7.8$ to $25^{*}$ & & & \\
\hline Harrouchi et al. (2016) & - & $\sim 0$ to $4^{*}$ & $1 / \mathrm{km}$ & unknown & unknown \\
\hline Hisarli et al. (2011) & $\sim 0$ to $0.4^{*}$ & $\sim 0.3$ to $0.5^{*}$ & $\mathrm{rad} / \mathrm{km}(?)$ & $90 \times 90 \mathrm{~km}$ & $50 \%$ \\
\hline Hsieh et al. (2014) & $\sim 0$ to $0.2^{*}$ & $\sim 0.2$ to $0.4^{*}$ & $1 / \mathrm{km}(?)$ & $250 \times 250 \mathrm{~km}$ & $96 \%$ \\
\hline Hussein et al. (2012) & $0.02-0.3$ fixed & $\begin{array}{l}0.5-0.8 \\
\text { fixed }\end{array}$ & $\mathrm{rad} / \mathrm{km}$ & $55 \times 55 \mathrm{~km}$ & $18 \%$ \\
\hline $\begin{array}{l}\text { Idárraga-García \& } \\
\text { Vargas (2017) }\end{array}$ & $\sim 0$ to $0.4^{*}$ & $\sim 0.5$ to $1.0^{*}$ & $\mathrm{rad} / \mathrm{km}$ & unknown & unkno \\
\hline Leseane et al. (2015) & $\sim 0.1$ to $0.2^{*}$ & unknown & $\mathrm{rad} / \mathrm{km}$ & $\begin{array}{l}\sim 120 \times 120 \\
\mathrm{~km}\end{array}$ & unk \\
\hline Li \& Wang (2013) & $\sim 0$ to $0.06^{*}$ & $\sim 0.4$ to $0.6^{*}$ & $1 / \mathrm{km}$ & $\begin{array}{l}208.8 \times \\
208.8 \mathrm{~km}\end{array}$ & $\sim 33 \%$ \\
\hline Li et al. (2017) & $\begin{array}{l}0.03-0.19 \\
\text { fixed }\end{array}$ & unknown & $1 / \mathrm{km}$ & $\begin{array}{l}98.8,195.0 \\
296.4 \mathrm{~km}\end{array}$ & $50 \%$ \\
\hline Manea \& Manea (2010) & $\begin{array}{l}0.05-0.2 \\
\text { fixed }\end{array}$ & $\begin{array}{l}0.6-0.9 \\
\text { fixed }\end{array}$ & $\mathrm{rad} / \mathrm{km}$ & $\begin{array}{l}\sim 220 \times 220 \\
\mathrm{~km}\end{array}$ & $\sim 25 \%$ \\
\hline Mono et al. (2018) & unknown & unknown & - & $-55 \times 55 \mathrm{~km}$ & $50 \%$ \\
\hline $\begin{array}{l}\text { Moraes Rocha et al. } \\
(2015)\end{array}$ & unknown & unknown & & $100 \times 100 \mathrm{~km}$ & $90 \%$ \\
\hline Mousa et al. (2017) & - & $\sim 1.8$ to $10.6^{*}$ & $\begin{array}{l}\text { cycle } / \mathrm{km} \\
(?)\end{array}$ & $60 \times 60 \mathrm{~km}$ & $50 \%$ \\
\hline Nwankwo (2015) & $\sim 0$ to $0.25^{*}$ & $\sim 0.2$ to $0.5^{*}$ & $\mathrm{rad} / \mathrm{km}$ & $\begin{array}{l}\sim 200 \mathrm{~km} \\
\text { profiles }\end{array}$ & - \\
\hline $\begin{array}{l}\text { Okubo \& Matsunaga } \\
\text { (1994) }\end{array}$ & $\sim 0.05$ to $0.2^{*}$ & & $\mathrm{rad} / \mathrm{km}$ & $\begin{array}{l}110 \text { to } 280 \\
\mathrm{~km} \text { profiles }\end{array}$ & - \\
\hline Okubo (1985) & unknown & unknown & - & $\begin{array}{l}60 \times 60 \text { to } 90 \\
\times 90 \mathrm{~km}\end{array}$ & $\sim 50 \%$ \\
\hline Okubo et al. (2003) & 0.03 to 0.12 & unknown & $1 / \mathrm{km}$ & $\begin{array}{l}160,320,640 \\
\mathrm{~km}\end{array}$ & unknown \\
\hline Qingqing et al. (2008) & $\begin{array}{l}0.005-0.05 \\
\text { fixed }\end{array}$ & $\begin{array}{l}0.05-0.1 \\
\text { fixed }\end{array}$ & $\mathrm{rad} / \mathrm{km}(?)$ & $100 \times 100 \mathrm{~km}$ & $50 \%$ \\
\hline Quintero et al. (2019) & $\sim 0$ to $0.6^{*}$ & $\sim 0$ to $0.6^{*}$ & $1 / \mathrm{km}(?)$ & $\begin{array}{l}100,200,300 \\
\mathrm{~km}\end{array}$ & 50 to $83 \%$ \\
\hline Rajaram et al. (2009) & unknown & $\sim 0-0.3 *$ & $\mathrm{rad} / \mathrm{km}$ & $\begin{array}{l}\sim 220 \times 220 \text { to } \\
\sim 660 \times 660 \\
\mathrm{~km}\end{array}$ & $\sim 50$ to $80 \%$ \\
\hline Ravat et al. (2007) & $0.1-0.2$ fixed $^{*}$ & - & $\mathrm{rad} / \mathrm{km}$ & - & - \\
\hline Rozimant et al. (2009) & $\sim 0$ to $0.4^{*}$ & $\sim 0$ to $0.4^{*}$ & $1 / \mathrm{km}$ & $100 \times 100 \mathrm{~km}$ & $50 \%$ \\
\hline Saibi et al, (2015) & $?$ & $\sim 0$ to $3.1^{*}$ & $1 / \mathrm{km}$ & $200 \times 200 \mathrm{~km}$ & unknown \\
\hline Salazar et al (2016) & $\sim 0-1.9^{*}$ & $\sim 2.5-6.9^{*}$ & cycle/km & $336 \times 336 \mathrm{~km}$ & $98 \%$ \\
\hline Saleh et al. (2012) & $\sim 0$ to $0.4^{*}$ & $\sim 0.2$ to $0.5^{*}$ & $\mathrm{rad} / \mathrm{km}(?)$ & $161 \times 161 \mathrm{~km}$ & $\sim 34 \%$ \\
\hline Salem et al. (2017) & $\sim 0$ to $6.2 *$ & - & cycle $/ \mathrm{km}$ & $40 \times 40 \mathrm{~km}$ & unknown \\
\hline Salk et al. (2005) & $\sim 0$ to $0.2^{*}(?)$ & $\sim 0$ to $0.2^{*}(?)$ & $\mathrm{rad} / \mathrm{km}$ & profiles & - \\
\hline Selim \& Aboud (2013) & $\sim 0$ to $0.6^{*}$ & $\sim 0.6$ to $2.5^{*}$ & cycle $/ \mathrm{km}$ & $100 \times 100 \mathrm{~km}$ & unknown \\
\hline
\end{tabular}




\begin{tabular}{|l|l|l|l|l|l|} 
Spector \& Grant (1970) & - & 0.2 to $1.2^{*}$ & $\mathrm{rad} / \mathrm{km}$ & - & - \\
\hline $\begin{array}{l}\text { Stampolidis \& Tsokas } \\
(2002)\end{array}$ & unknown & unknown & - & $90 \times 90 \mathrm{~km}$ & unknown \\
\hline Tanaka et al (1999) & $\sim 0$ to $0.3^{*}$ & $\sim 0.3$ to $0.6^{*}$ & $1 / \mathrm{km}$ & $\begin{array}{l}\sim 200 \times 200 \\
\mathrm{~km}\end{array}$ & \\
\hline Tanaka et al (2017) & $\sim 0$ to 0.1 & - & $1 / \mathrm{km}$ & $\begin{array}{l}\sim 350 \times 350 \\
\mathrm{~km}\end{array}$ & $\sim 33 \%$ \\
\hline $\begin{array}{l}\text { Tanaka \& Ishikawa } \\
(2005)\end{array}$ & $\sim 0-0.3$ & $\sim 0.3-6$ & $1 / \mathrm{km}$ & $\begin{array}{l}\sim 236 \times 236 \\
\mathrm{~km}\end{array}$ & uneven \\
\hline Trifonova et al. (2009) & $\sim 0$ to $3^{*}$ & $\sim 0.3$ to 0.6 & $1 / \mathrm{km}$ & unknown & unknown \\
\hline Tselentis (1991) & unknown & unknown & - & $64 \times 64 \mathrm{~km}$ & unknown \\
\hline Tsokas et al. (1998) & unknown & unknown & - & $91 \times 91 \mathrm{~km}$ & $50 \%$ \\
\hline Tsvetkov et al. (2018) & $\sim 0$ to $1.8^{*}$ & unknown & $1 / \mathrm{km}$ & profiles & - \\
\hline Twinkle et al. (2016) & $0.03-0.3$ fixed & $\begin{array}{l}0.3-0.5 \\
\text { fixed }\end{array}$ & $1 / \mathrm{km}$ & general & - \\
\hline Vargas et al. (2015) & $\sim 0$ to $1.8^{*}$ & $\sim 2.5$ to $6.9^{*}$ & cycle $/ \mathrm{km}$ & $\begin{array}{l}250,300,380 \\
\mathrm{~km}\end{array}$ & $\sim 98 \%$ \\
\hline Xi et al. (2015) & $\sim 0.1$ to $0.3^{*}$ & $\sim 0.4$ to $0.8^{*}$ & $\mathrm{rad} / \mathrm{km}$ & $160 \times 160 \mathrm{~km}$ & $20 \%$ \\
\hline Xiong et al. (2016) & unknown & unknown & - & $100 \times 100 \mathrm{~km}$ & $50 \%$ \\
\hline
\end{tabular}



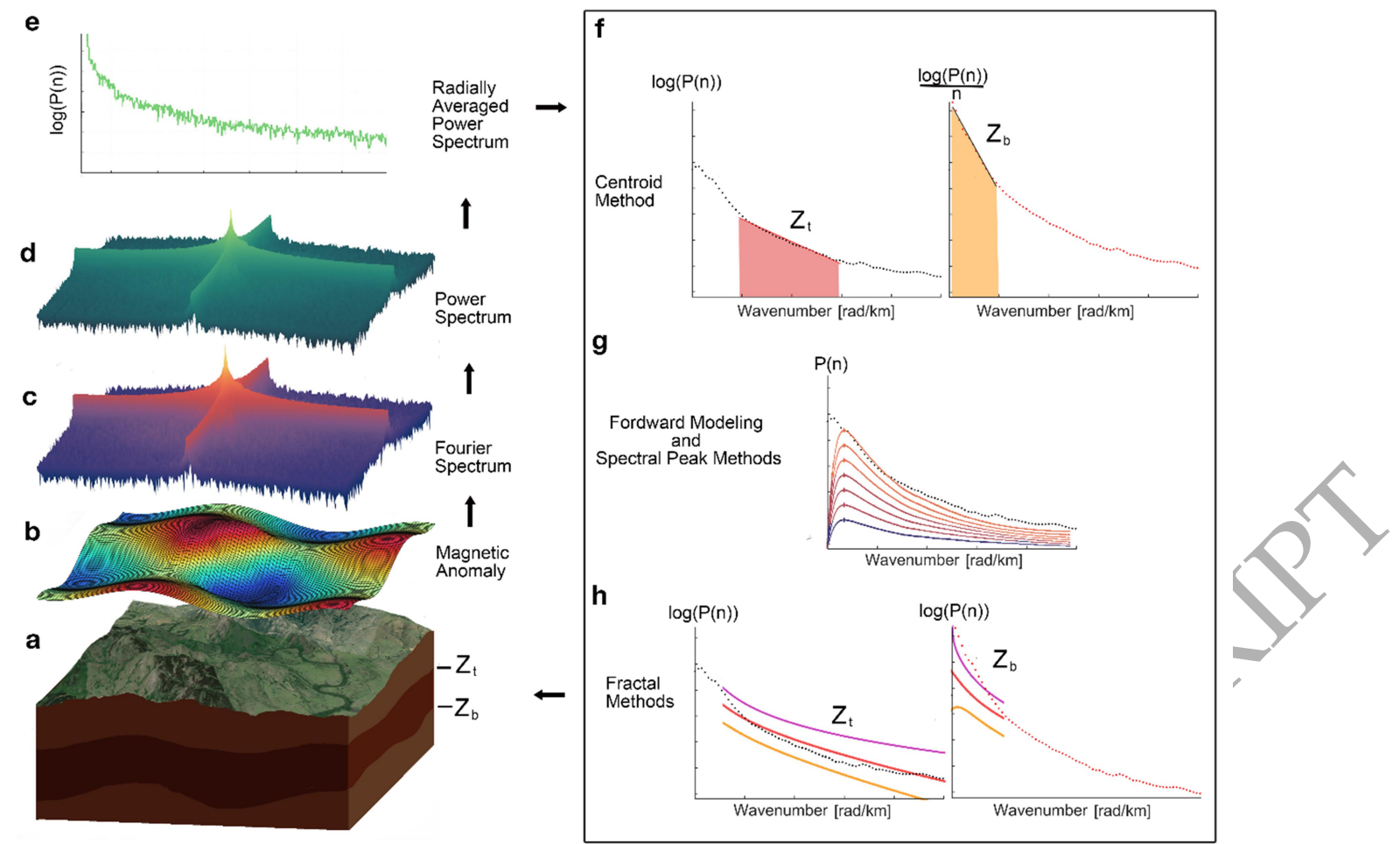

Figure 1. Illustration of the different steps in Curie depth spectral methods: The magnetic source located between $Z_{t}$, and $Z_{b}$ depths (a) generates a 2D magnetic anomaly (b) with a $2 \mathrm{D}$ Fourier spectrum (c). The 2D power spectra is calculated (d) and averaged radially (e). In the centroid method the $Z_{t}$, and $Z_{b}$ depths are calculated trough linear adjustments in the power spectra and in the scaled amplitude spectral density respectively (f). In the Forward modeling method a theoretical curve, indicated by coloured lines, is adjusted to the power spectra (g). In the simplified Fractal method, equations are adjusted to different spectra variations (coloured lines) in order to calculate $\mathrm{Z}_{\mathrm{t}}$, and $\mathrm{Z}_{\mathrm{b}}$ depths (h). 

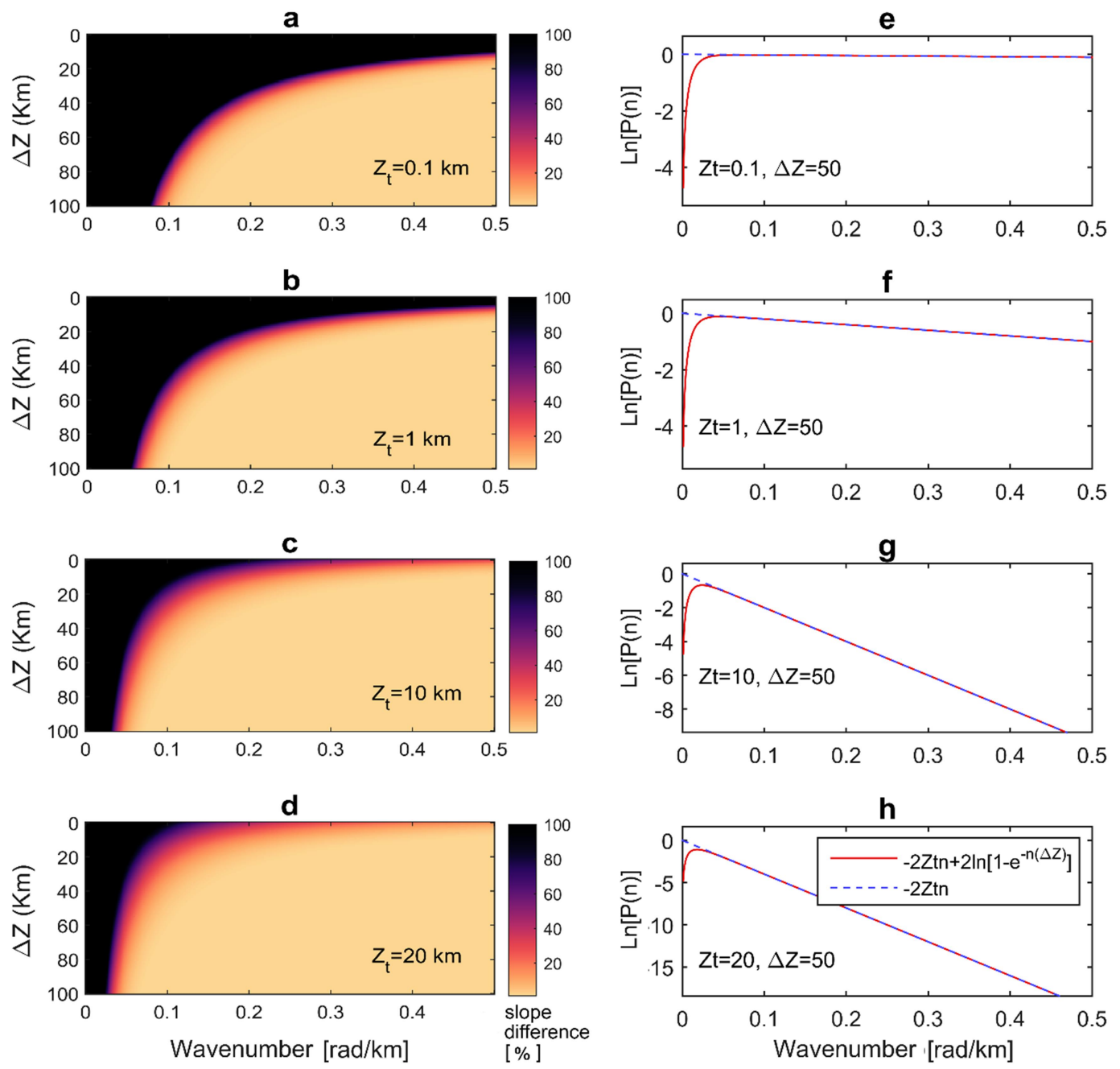

Figure 2. Confidence regions for the calculus of the depth to the top of the magnetic source $\left(Z_{t}\right)$. Plots (a), (b), (c) and (d) present the discrete percentage absolute slope difference (eq. 11) between curves corresponding to eqs (4) and (5) for different values of $n, \mathrm{Z}_{\mathrm{t}}$, and $\Delta \mathrm{Z}=\left(\mathrm{Z}_{\mathrm{b}}\right.$ $\left.Z_{t}\right)=2 .\left(Z_{0}-Z_{t}\right)$. Note that as $Z_{t}$ is the slope in eq. (5), the slope difference represents directly the $Z_{t}$ difference in $\mathrm{km}$. Light colors depict the wavenumber range in which the difference between curves is close to zero (on other words, when eq.4 and 5 are equivalent). (a) $Z_{t}=0.1 \mathrm{~km}$, (b) $Z_{t}$ $=1 \mathrm{~km},(\mathbf{c}) Z_{\mathrm{t}}=10 \mathrm{~km},(\mathbf{d}) \mathrm{Z}_{\mathrm{t}}=20 \mathrm{~km}$. Plots (e), (f), (g) and( h) present curves corresponding to eqs (4) (red) and (5) (blue, dashed line) for the particular case of $\Delta \mathrm{Z}=50$ and different values of $Z_{\mathrm{t}},\left(\right.$ e) $Z_{\mathrm{t}}=0.1 \mathrm{~km},(\mathbf{f}) \mathrm{Z}_{\mathrm{t}}=1 \mathrm{~km},\left(\right.$ g) $Z_{\mathrm{t}}=10 \mathrm{~km},(\mathbf{h}) Z_{\mathrm{t}}=20 \mathrm{~km}$. 

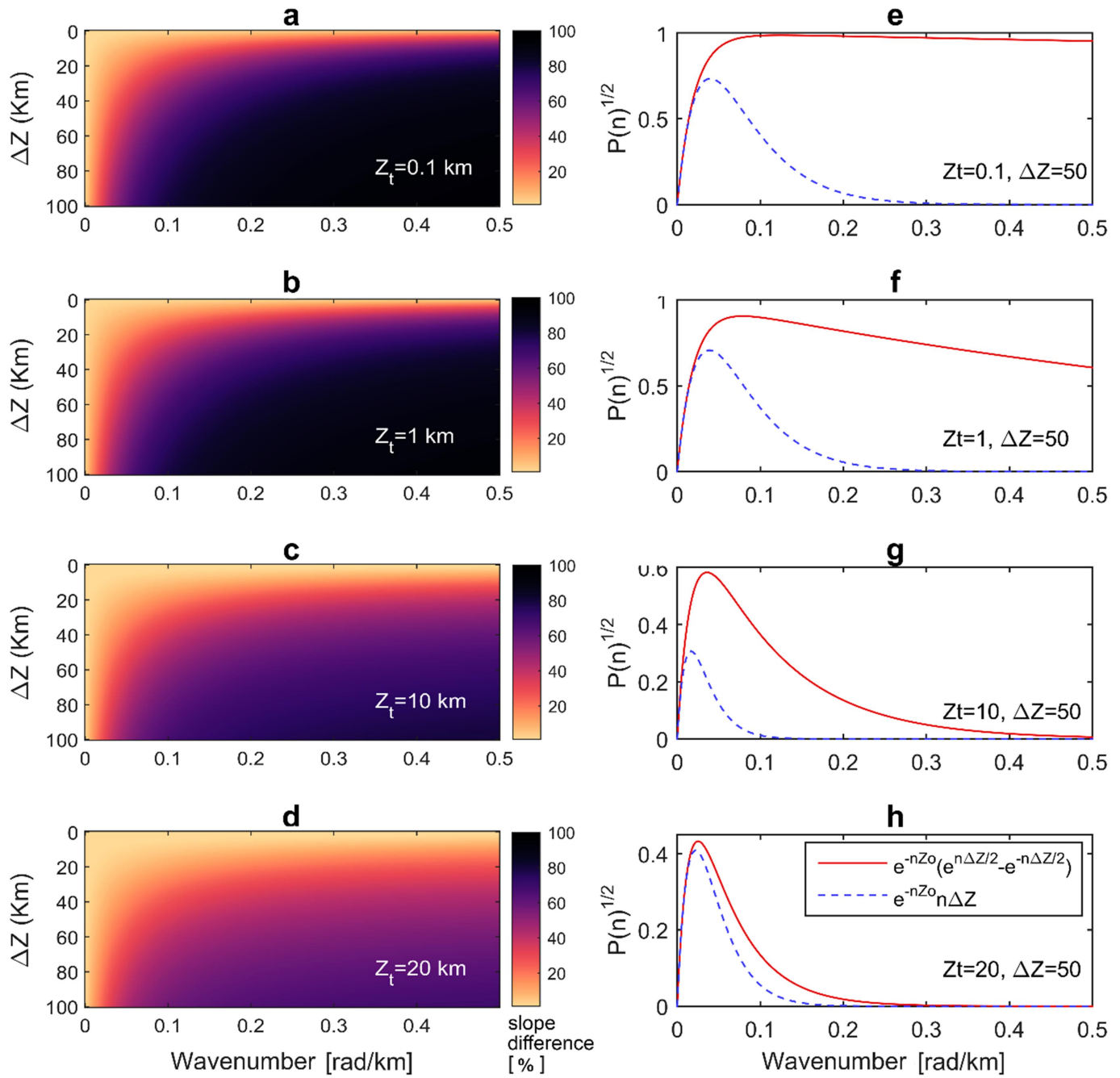

Figure 3. Confidence regions for the calculus of the depth to the centroid of the magnetic source $\left(Z_{\mathrm{o}}\right)$. Plots (a), (b), (c) and (d) present the percentage absolute slope difference (eq. 11) between curves corresponding to eqs (7) and (8) for different values of $n, Z_{t}$, and $\Delta \mathrm{Z}=\left(\mathrm{Z}_{\mathrm{b}}\right.$ $\left.Z_{t}\right)=2 .\left(Z_{0}-Z_{t}\right)$. Slope difference was calculated dividing eqs (7) and (8), by $n$ and applying logarithm so the slopes represent depths as in eq. (9). In this conditions, the slope difference represents directly the $Z_{o}$ difference in $\mathrm{km}$. Light colors depict the wavenumber range in which eqs (7) and (8) are equivalent. (i) $Z_{t}=0.1 \mathrm{~km},(\mathbf{j}) Z_{t}=1 \mathrm{~km},(\mathbf{k}) Z_{t}=10 \mathrm{~km}$, (l) $Z_{t}=20 \mathrm{~km}$. Plots (e), (f), (g), and (h) present curves corresponding to eqs (7) (red) and (8) (blue dashed line) for $\Delta Z=50$ and different values of $Z_{t},\left(\right.$ e) $Z_{\mathrm{t}}=0.1 \mathrm{~km},\left(\right.$ f) $Z_{\mathrm{t}}=1 \mathrm{~km},\left(\right.$ g) $Z_{\mathrm{t}}=10 \mathrm{~km}$, (h) $Z_{\mathrm{t}}=20 \mathrm{~km}$. 

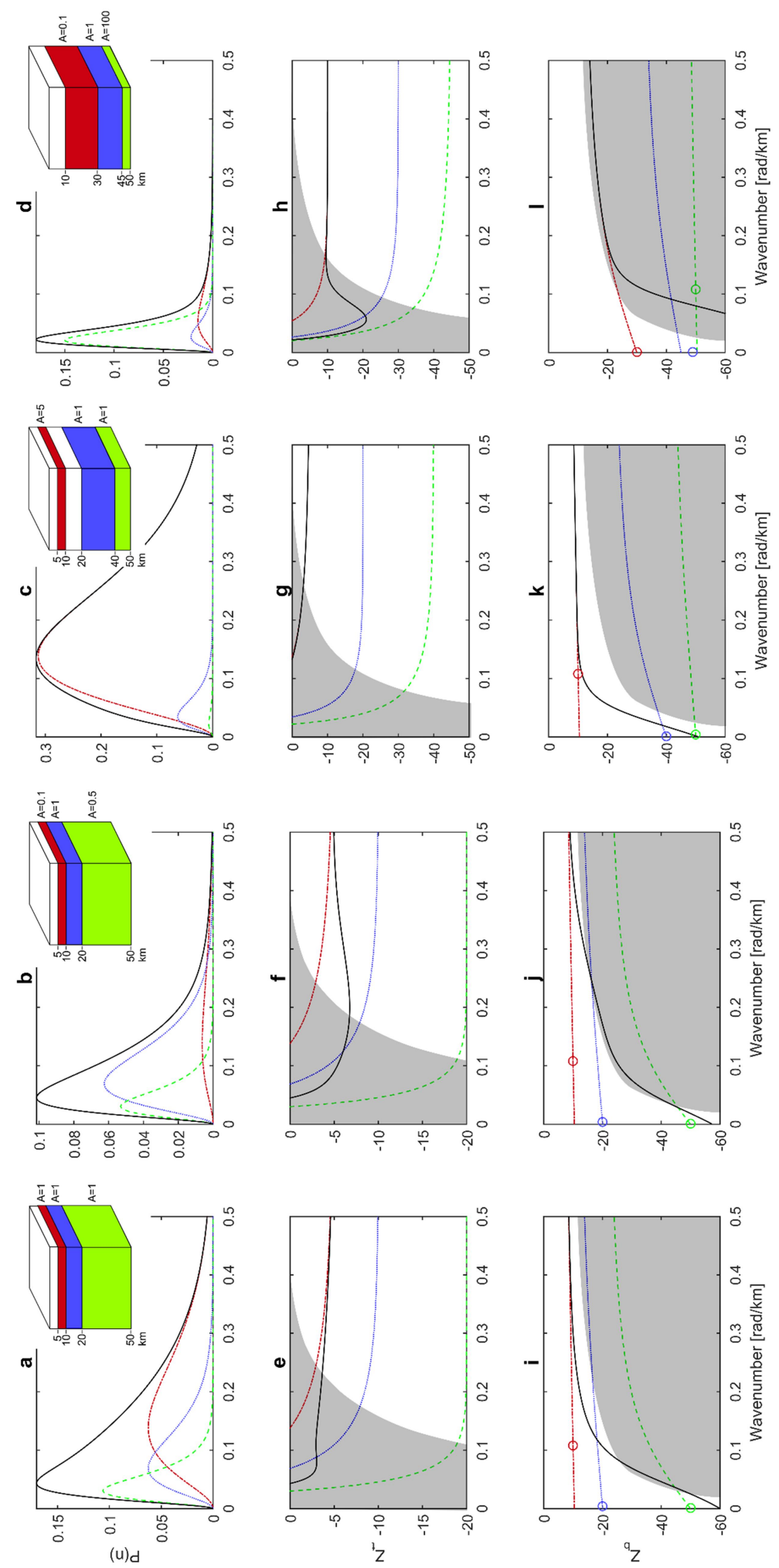

Figure 4. Multilayer synthetic models - Figs (a), (b), (c) and (d) show the model configuration and the power spectra produced by each layer of the same color, according to eq. (3), (top layer: dot-dash line, medium layer: dotted line, bottom layer dashed line) and the sum of the spectra 
(continuous black line). Each column of plots represent the same model. Figs (e), (f), (g) and (h) represent $Z_{t}$ values calculated according to eq. (6) for each discrete segment of the spectra. Figs (i), (j), (k) and (1) represent $Z_{b}$ value calculated according to eqs. (9) and (10) for each discrete segment of the spectra. Grey areas show the regions in which, $Z_{t}$ and $Z_{b}$ should not be calculated according to Figs 2 and 3. 

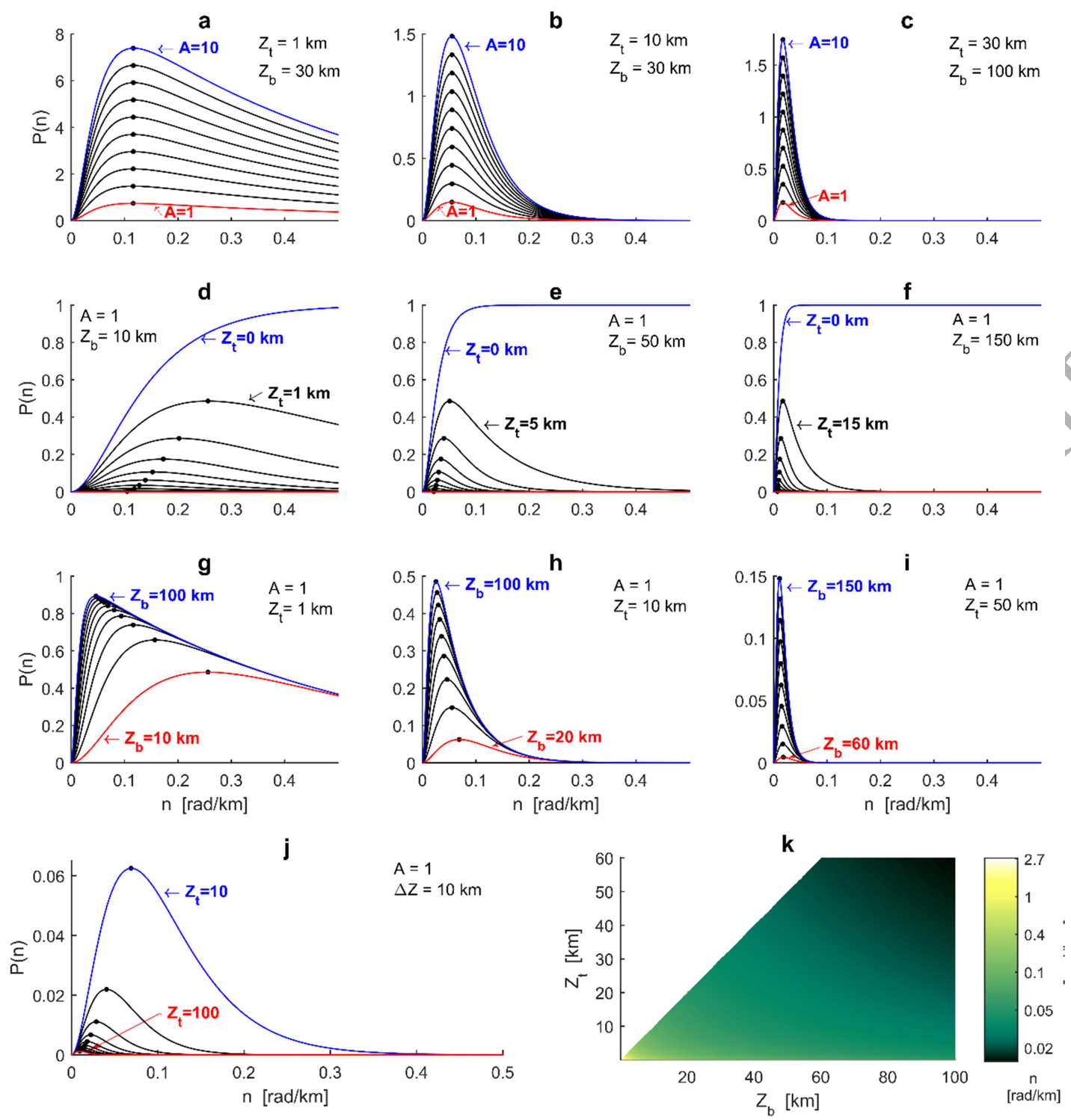

Figure 5. Effects of the variation of parameters in eq. (12): $Z_{t}$ and $Z_{b}$ the depth to the top and bottom of the magnetic layer respectively; and Aa constant that represents the condensed magnetic properties. The spectral peak is indicated as a point in the different plots - when it exists- (a), (b), (c) Effects of the variation of the constant $A$ from 1 to 10 , with $\mathrm{Z}_{\mathrm{t}}$ and $\mathrm{Z}_{\mathrm{b}}$ fixed. (d), (e), (f) Effects of the variation of $Z_{t}$ - for 10 equi-spaced values between $0 \mathrm{~km}$ and $Z_{b}$-, with

2 parameters $A$ and $Z_{\mathrm{b}}$ fixed. (g), (h), (i) Effects of the variation of $Z_{\mathrm{b}}$ - for 10 equi-spaced values with parameters $A$ and $Z_{t}$ fixed. (j) Effects of the variation of $Z_{t}$ - for 10 equi-spaced values 
between 10 and $100 \mathrm{~km}$ - with $\mathrm{A}$ and $\Delta \mathrm{Z}=\left(\mathrm{Z}_{\mathrm{b}}-\mathrm{Z}_{\mathrm{t}}\right)$ fixed. (k) Position of the spectral peak $\left(n_{\max }\right)$ by varying parameters $Z_{t}$ and $Z_{b}$ according to eq. 12 . 

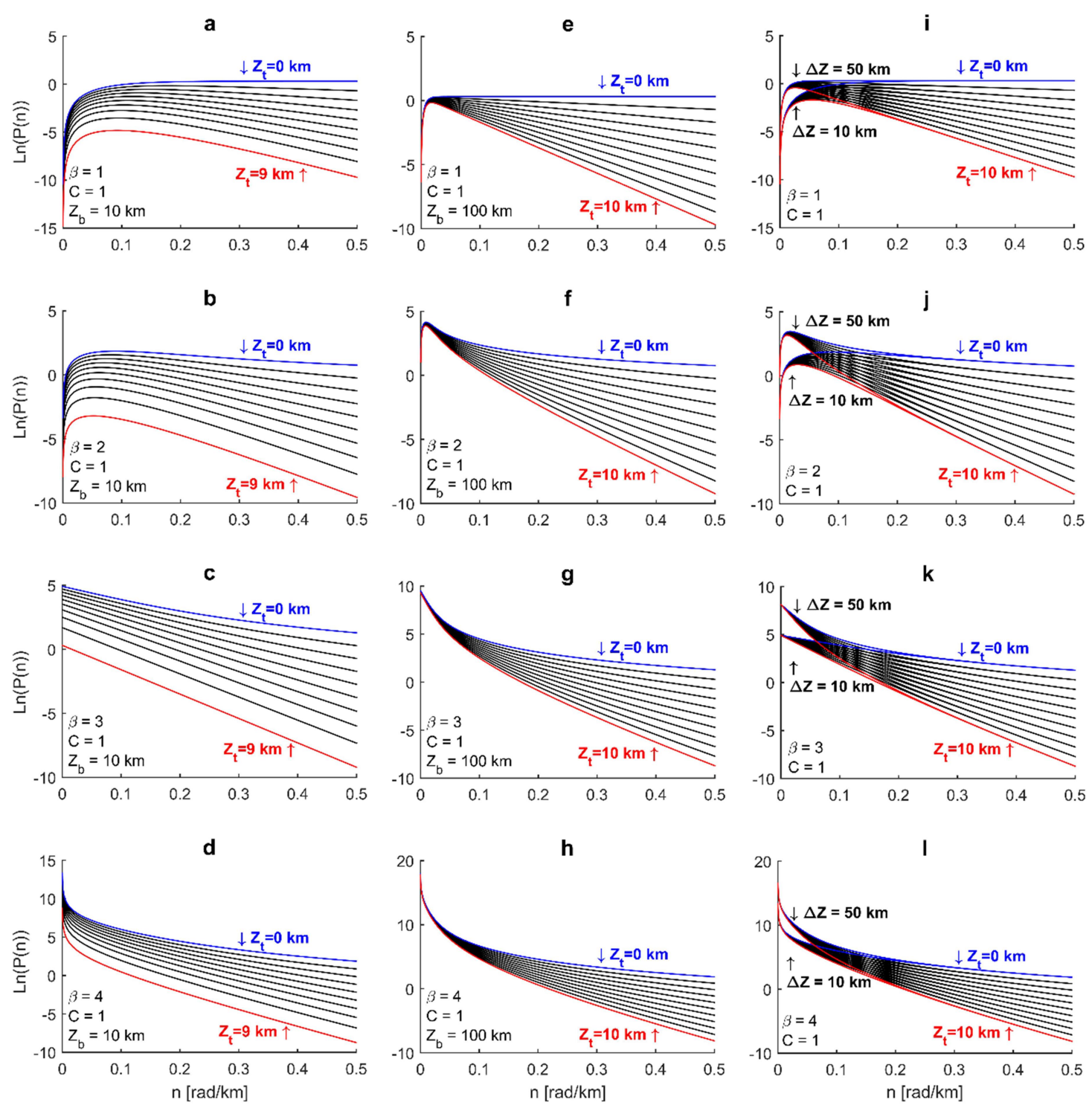

Figure 6. Effects of the variation of parameters in eq. (15): the fractal exponent $\beta$, the depth to the top and bottom of the magnetic source, $Z_{t}$, and $Z_{b}$ respectively; and $\Delta \mathrm{Z}$ the thickness of the magnetic source . a, b, c, d) shows the effects of the variation of $Z_{\mathrm{t}}$ from 0 to $9 \mathrm{~km}$, using different $\beta$ values and with $C=1$, and $Z_{b}=10 \mathrm{~km}$ fixed. e, $\left.\mathbf{f}, \mathbf{g}, \mathbf{h}\right)$ shows the effects of the variation of $Z_{t}$ from 0 to $100 \mathrm{~km}$, with $10 \mathrm{~km}$ steps, using different $\beta$ values and with $C=1$, and $Z_{b}=100 \mathrm{~km}$ fixed. $\left.\mathbf{i}, \mathbf{j}, \mathbf{k}, \mathbf{l}\right)$ shows the effects of the variation of $Z_{t}$ from 0 to $10 \mathrm{~km}$, with $1 \mathrm{~km}$ steps, using different $\beta$ values and with $\mathrm{C}=1$, for two different $\Delta \mathrm{Z}$ values. 

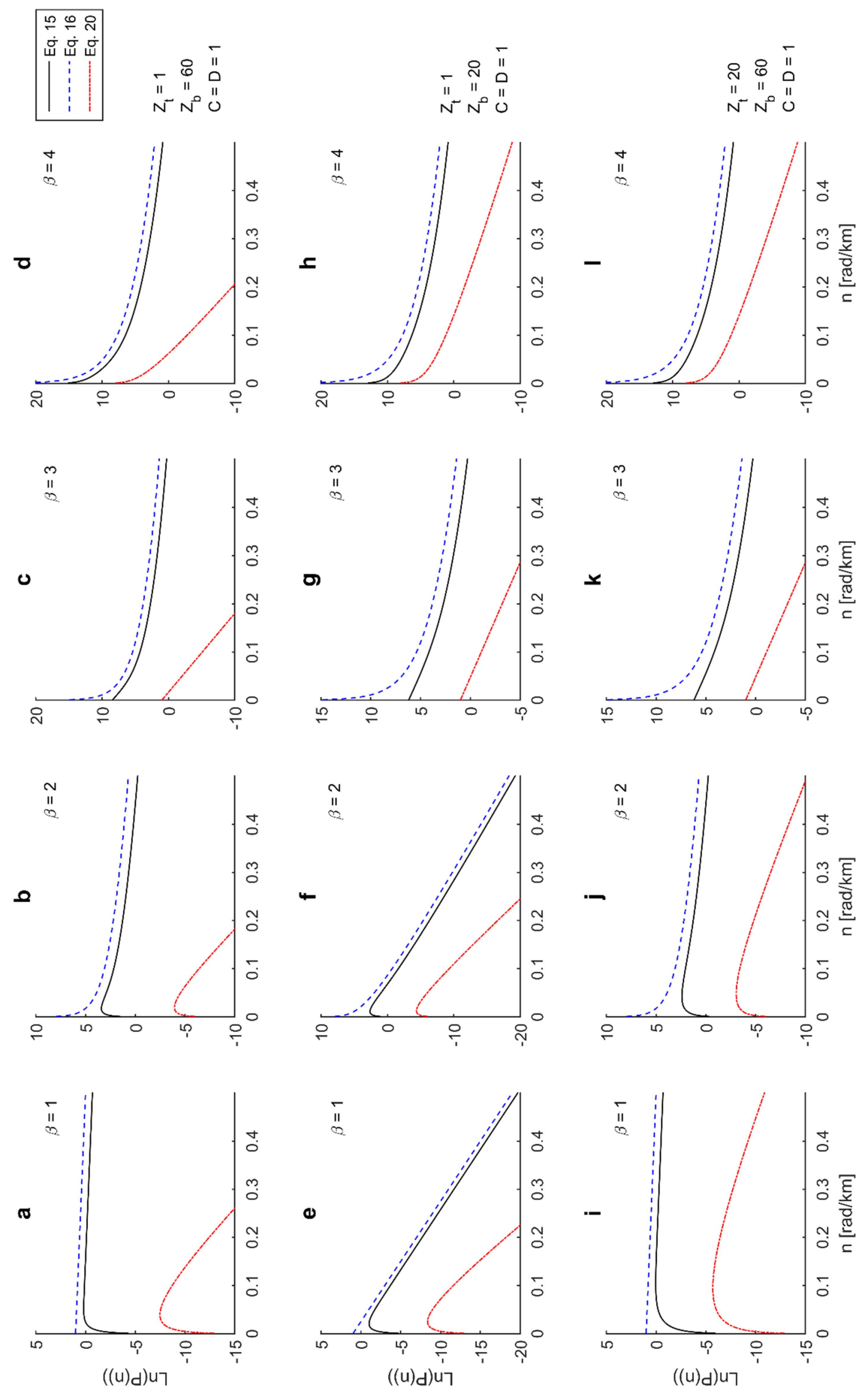

Figure 7. Comparison between eqs. (15), (16) and (20) under different conditions. Figures in the same row share the same parameters indicated to the right: $\mathrm{C}$ and $\mathrm{D}$, are constants that 
condense the magnetic properties, $\mathrm{Z}_{\mathrm{t}}$ and $\mathrm{Z}_{\mathrm{b}}$ are the depth to the top and bottom of the magnetic source, respectivelly. Figures in the same column share the same fractal constant $\beta$ value, indicated in the upper corner of each plot. 

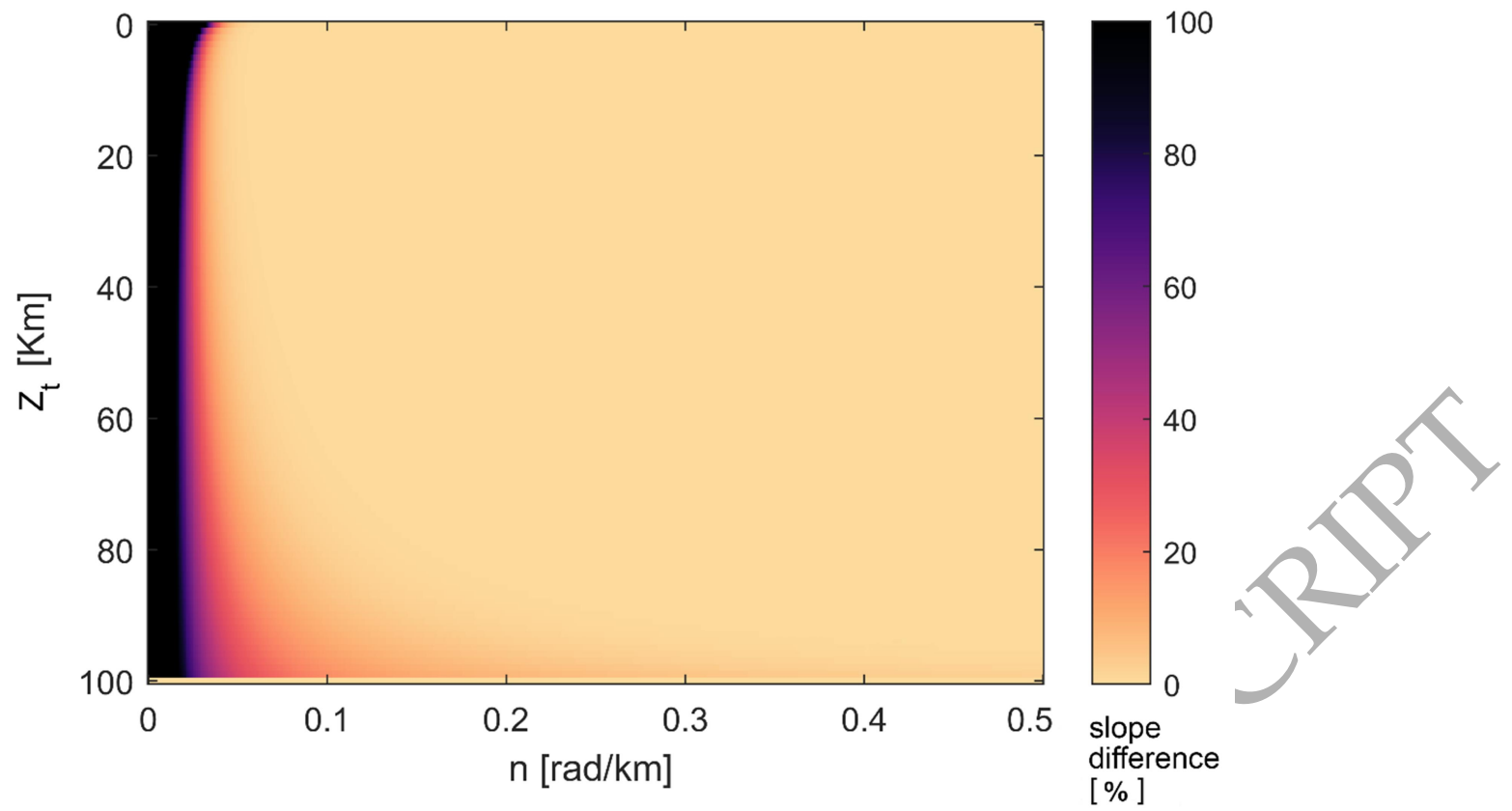

Figure 8. Confidence regions for the calculation of the depth to the top of the magnetic sources $\left(Z_{t}\right)$ in the simplified fractal method. Plots show the percentage slope difference (eq. (11)) between the curves corresponding to eqs. (16) and (15) for different wavenumbers $(n)$ and for varying values of $Z_{\mathrm{t}}$. $Z_{\mathrm{b}}$ is fixed at $100 \mathrm{~km}$. Variations in the constant $C$ or $\beta$ produce the same results. 

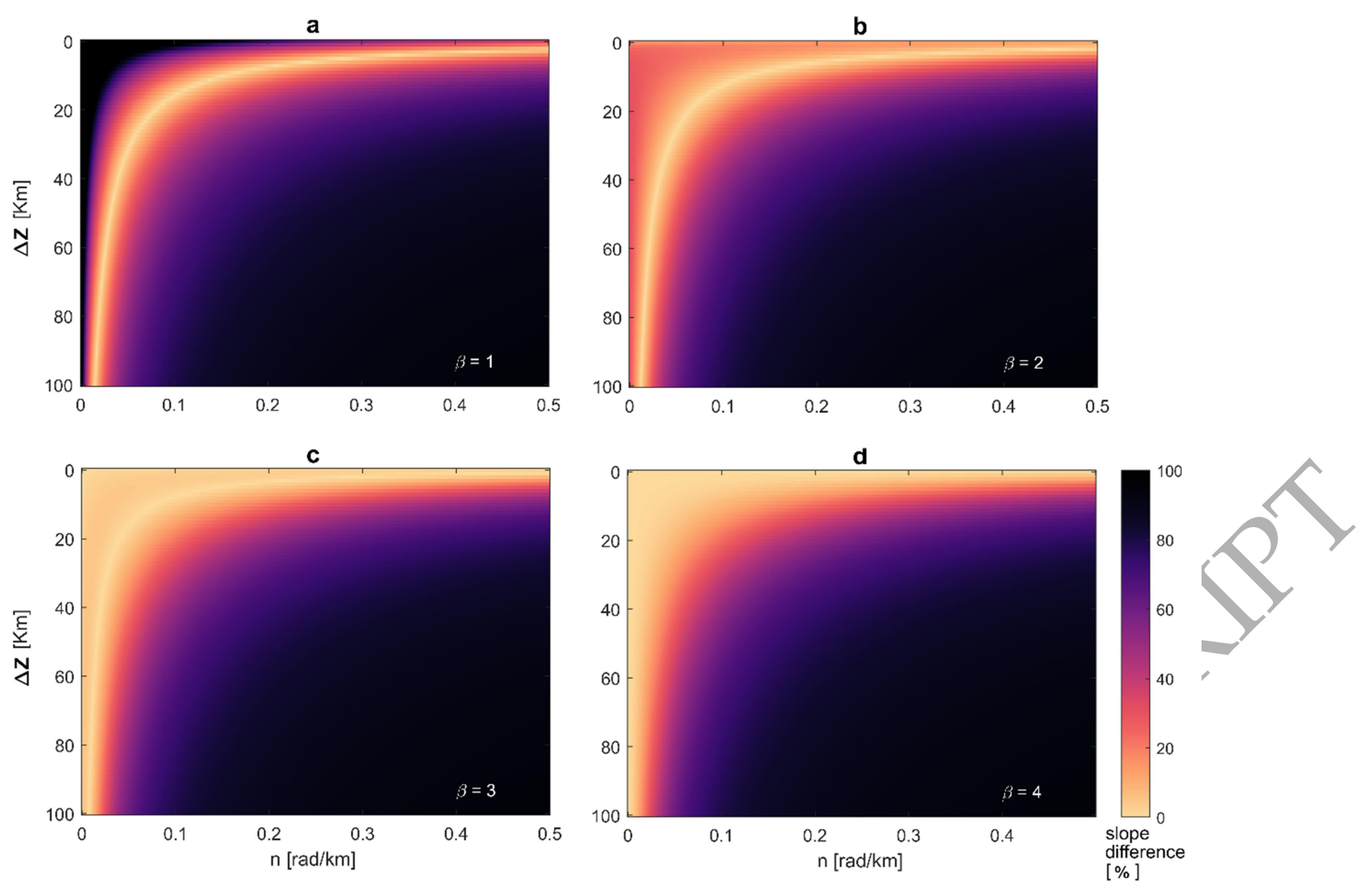

Figure 9. Confidence regions for the calculation of the depth to the centroid of the magnetic sources $\left(Z_{o}\right)$ in the simplified fractal method. Plots show the percentage slope difference (eq. 11) between the curves corresponding to eqs (20) and (15) for different wavenumbers $(n)$ and $\Delta \mathrm{Z}$ values and with $Z_{\mathrm{t}}$ fixed at $1 \mathrm{~km}$. Figs (a), (b), (c), (d), correspond to different $\beta$ values. Light colors depict the interval in which eqs (20) and (15) have similar slopes. 